\title{
Challenges and benefits of quantifying irrigation through the assimilation of Sentinel-1 backscatter observations into Noah-MP
}

\author{
Sara Modanesi ${ }^{1,2,3}$, Christian Massari ${ }^{1}$, Michel Bechtold ${ }^{2}$, Hans Lievens ${ }^{2}$, Angelica Tarpanelli ${ }^{1}$, Luca \\ Brocca $^{1}$, Luca Zappa ${ }^{4}$, Gabriëlle J. M. De Lannoy ${ }^{2}$ \\ $5{ }^{1}$ Research Institute for Geo-hydrological Protection, National Research Council, Via della Madonna Alta 126, 06128 Perugia, Italy \\ ${ }^{2}$ Department of Earth and Environmental Sciences, KU Leuven, Heverlee, Belgium \\ ${ }^{3}$ DICEA Dept. of Civil and Environmental Engineering, University of Florence, Via di S. Marta 3, 50139 Firenze, Italy \\ ${ }^{4}$ Department of Geodesy and Geoinformation, Technische Universität Wien (TU Wien), Wiedner Hauptstraße 8-10, 1040 Vienna, Austria
}

Correspondence to: Christian Massari (christian.massari@irpi.cnr.it)

10 Abstract. In recent years, the amount of water used for agricultural purposes has been rising due to an increase in food demand. However, anthropogenic water usage, such as for irrigation, is still not or poorly parameterized in regional and larger-scale land surface models (LSM). By contrast, satellite observations are directly affected by, and hence potentially able to detect, irrigation as they sense the entire integrated soil-vegetation system. By integrating satellite observations and fine-scale modelling it could thus be possible to improve estimation of irrigation amounts at the desired spatial-temporal scale.

15 In this study we tested the potential information offered by Sentinel-1 backscatter observations to improve irrigation estimates, in the framework of a data assimilation (DA) system composed by the Noah-MP LSM, equipped with a sprinkler irrigation scheme, and a backscatter operator represented by a Water Cloud Model (WCM), as part of the NASA Land Information System (LIS). The calibrated WCM was used as an observation operator in the DA system to map model surface soil moisture and leaf area index (LAI) into backscatter predictions and, conversely, map observation-minus-forecast backscatter residuals back to updates in soil moisture and LAI through an ensemble Kalman filter (EnKF).

The benefits of Sentinel-1 backscatter observation in two different polarizations (VV and VH) were tested in two separate DA experiments, performed over two irrigated sites, the first one located in the Po Valley (Italy) and the second one located in northern Germany. The results confirm that VV backscatter has a stronger link with soil moisture than VH backscatter, whereas VH backscatter observations introduce larger updates in the vegetation state variables. The backscatter DA introduced both improvements and degradations in soil moisture, evapotranspiration and irrigation estimates. The spatial and temporal scale had large impacts on the analysis, with more contradicting results obtained for the evaluation at the fine agriculture scale (i.e., field scale). Above all, this study sheds light on the limitations resulting from a poorly-parameterized sprinkler irrigation scheme which prevents improvements in the irrigation simulation due to DA, and points to future developments needed to improve the system. 
https://doi.org/10.5194/hess-2022-61

Hydrology and

Preprint. Discussion started: 2 March 2022

(c) Author(s) 2022. CC BY 4.0 License.

\section{INTRODUCTION}

Irrigation has been applied by humans for as long as they have been cultivating plants. However, in the last century irrigation has become one of the most impactful human activities on the terrestrial water cycle, accounting for nearly $85 \%$ of the global water consumption (Gleick, 2003; Kustu et al., 2010) and for the 40\% of the world's food production (Foley et al., 2011; Massari et al., 2021; Siebert and Döll, 2010).

35 In the next decades, the foreseen increase in population (FAO, 2009) and climate change is expected to ask for larger amounts of water resources for food production and consequently increases in irrigation applications (Matthews and Germain, 2007; Ozdogan et al., 2010b). Busschaert et al. (2022) found that under a high CO2 emission scenario a significant increase in net irrigation requirements for all of Europe $(+30 \%$ during the summer months) is expected by the end of the century. Even though accurate information on farmer's decisions related to quantities and timing of irrigation applications are often not available for public use, it is critical to understand how much water is used for irrigation to design an optimal water management strategy and to understand the consequences of irrigation on climate in the future (Alter et al., 2015).

Therefore, many studies have focused on detecting and quantifying irrigation through modelling and remote sensing (RS) observations. From the modelling perspective, Girotto et al. (2017) highlighted the key role in representing anthropogenic processes into land surface models (LSM). The authors realized a study in India, where irrigation provides a large contribution to winter crop production, and they found that data assimilation (DA) of total water storage (TWS) RS observations into the Catchment land surface model (CLSM) introduces a negative trend in groundwater due to pumping for irrigation along with an associated erroneous negative trend in modelled evapotranspiration when irrigation is unmodelled. Other studies have attempted to incorporate irrigation schemes into global LSMs, including the Interaction between Soil, Biosphere, and Atmosphere (ISBA) LSM (Druel et al., 2021), the Community Land Model (CLM; Pokhrel et al., 2012) and the Organizing

50 Carbon and Hydrology in Dynamic Ecosystems (ORCHIDEE) model (De Rosnay et al., 2003), demonstrating the regional impact of irrigation on different water storages and on energy partitioning between sensible and latent heat fluxes (Lawston et al., 2015). Different types of irrigation systems were also implemented into the NASA Land Information System (LIS) framework and coupled with several LSMs, such as the Noah LSM (Chen et al., 1996; Chen and Dudhia, 2001; Mahrt and Pan, 1984) and the Noah-MP LSM (Niu et al., 2011). Drip and flood irrigation systems (Evans and Zaitchik, 2008) as well as

55 a sprinkler scheme (Ozdogan et al., 2010a) are currently part of the LIS framework. The sprinkler irrigation scheme, in particular, adds irrigation water as fictitious rainfall based on a root-zone soil moisture threshold and it was recently improved accounting for groundwater extraction in Nie et al. (2019).

Beyond these efforts, the human influence on the water distribution is still poorly described in LSMs due to simplifying assumptions, such as limitations related to soil texture maps, static crop maps or irrigation intensity inputs (Modanesi et al.,

60 2021; Monfreda et al., 2008; Ozdogan et al., 2010a; Salmon et al., 2015). Another key issue is related to the farmer's irrigation application decision, which is not necessarily related to crop irrigation requirements or based on the root-zone soil moisture availability but mainly on water resources availability (Massari et al., 2021). 
On the other hand, RS observations can indirectly disclose the presence of irrigation activities, when they sense the entire integrated soil-vegetation system. For instance, visible and near-infrared measurements were mainly used in previous studies

65 for developing irrigation mapping techniques (Ambika et al., 2016; Ozdogan and Gutman, 2008; Peña-Arancibia et al., 2014; Salmon et al., 2015) and, in recent years, optical data were also combined with microwave (MW) observations to investigate advantages of multi-sensor approaches (Ferrant et al., 2019). On the other hand, MW satellite data were exploited in the last decade for both detecting (Dari et al., 2021; Gao et al., 2018; Kumar et al., 2015) and quantifying irrigation (Brocca et al., 2018; Dari et al., 2020; Jalilvand et al., 2019; Zaussinger et al., 2019). All those studies highlighted the importance of high 70 spatial resolution of RS observations for a better estimation of irrigation quantities. In this context, the Copernicus Sentinel-1 mission represents the new era of satellite observations, providing Synthetic Aperture Radar (SAR) backscatter data at a fine spatial resolution (up to $10-20 \mathrm{~m}$ ) since 2014, which are freely accessible. Despite the advances in RS, satellite observations are still characterized by limitations, such as the low revisit time typically associated to higher spatial resolution data, noise in the measurements, and the uncertainties of satellite retrieval algorithms.

75 The optimal integration of fine-scale modelling and satellite observations using DA in LSMs could be a promising solution to account for anthropogenic activities and alongside improve the estimation of irrigation amounts and model predictions. Lawston et al. (2017) suggested the use of MW surface soil moisture (i.e., SMAP) to incorporate the irrigation signal into models via DA and further studies investigated the use of surface soil moisture retrievals and vegetation indices such as leaf area index (LAI) or vegetation optical depth to improve model predictions (Albergel et al., 2018; De Lannoy and Reichle,

80 2016; Kumar et al., 2020). However, MW-based retrievals could also add unreliable information into LSM systems due to lacking or inconsistent ancillary data used in RS observations pre-processing and the retrieval algorithm. To avoid this limitation, previous studies investigated the direct assimilation of MW observations, such as brightness temperature (Tb) derived from Soil Moisture and Ocean Salinity (SMOS) or Soil Moisture Active Passive (SMAP) missions (De Lannoy and Reichle, 2016; Reichle et al., 2019), radar backscatter from the Advanced Scatterometer (ASCAT; Lievens et al., 2017a), or

85 the joint assimilation of Sentinel-1 backscatter and SMAP Tb (Lievens et al., 2017b), through the use of calibrated observation operators.

Those earlier studies on the direct assimilation of MW observations did not include any irrigation or dynamic vegetation modelling. Consequently, they did not investigate the benefits of jointly updating soil moisture and vegetation, or any consequences on irrigation estimation. This work aims at filling those gaps using the Noah-MP v.3.6 (Niu et al., 2011) equipped

90 with a dynamic vegetation model, a sprinkler irrigation scheme (Ozdogan et al., 2010a), and a calibrated backscatter forward operator, being the Water Cloud Model (WCM; Attema and Ulaby; 1978), within the NASA LIS framework. The main target of this study is then to assimilate $1 \mathrm{~km}$ Sentinel-1 radar backscatter observations for a joint update of modelled soil moisture and vegetation in order to correct them for actual irrigation applications and thereby improve the initial land surface conditions for subsequent irrigation forecasts. The backscatter from Sentinel-1 contains information on both soil moisture (Bauer-

95 Marschallinger et al., 2018; Liu and Shi, 2016; Zribi et al., 2011) and vegetation (Vreugdenhil et al., 2020, 2018) and we hypothesize that assimilating these data could correct for misrepresented or missed irrigation events. Furthermore, we assume 
that when coupling the Noah-MP DA system with a poorly parameterized sprinkler irrigation module, irrigation water amounts can be optimally estimated when optimal soil moisture and vegetation estimates are available. In this framework, the WCM calibration is a necessary step to obtain unbiased predictions over intensively irrigated areas and this topic was deeply investigated in Modanesi et al. (2021). With the support of a near-optimal DA system, this study aims at improving irrigation estimates and the following points are discussed:

i) the improvement (or deterioration) of LSMs simulations in terms of irrigation, soil moisture, vegetation and evapotranspiration due to the sequential assimilation of Sentinel-1 backscatter in vertical transmit and receive $(\mathrm{VV})$ or in vertical transmit and horizontal receive $(\mathrm{VH})$ polarizations, and the differences in results obtained using co- and cross-polarization observations to update both soil moisture and vegetation;

ii) the limitations due to the spatial scale, and shortcomings of the system in terms of model parameterization and DA consistency.

The analysis was carried out over two pilot sites: i) the Po Valley, one of the most intensively cultivated and irrigated areas in Italy (Po River Watershed Authority, 2016); and ii) an irrigated area located in northern Germany, in more humid conditions.

110 The paper is organized as follows. Section 2 describes the study areas, the datasets used (i.e., in situ benchmark data and RS observations), methods (including the LSM description and the DA system) and the experimental setup. Section 3 presents the results obtained from the DA experiments: first the quality of the DA system design is evaluated in terms of DA diagnostics and then the estimates of irrigation and model state variables and fluxes are evaluated. In Section 4 we provide a discussion, and conclusions are reported in Section 5.

\section{DATA AND METHODS}

\subsection{Study areas and in situ data}

Two European pilot sites characterized by different climatic conditions were selected (Figure 1). The first one is located in the Niedersachsen region in Northern Germany and has an extent of $160 \mathrm{~km}^{2}$, marked by the transparent red box in Figure $1 \mathrm{a}$. It can be classified as Cfb (temperate oceanic climate) in the Koeppen-Geiger classification (Peel et al., 2007). Mean annual temperature and precipitation are around $9{ }^{\circ} \mathrm{C}$ and $550 \mathrm{~mm}$, respectively. For more general information on this pilot site the reader can refer to the work by Zappa et al. (2021). The test site is composed of 49 fields characterized by a wide variety of crops, which include potatoes, sugar beet, summer barley and winter wheat. Daily irrigation data, available for each field, were provided for the year 2018.

The second pilot site is located within the Po Valley, one of the most important agricultural areas in Italy, intensively equipped for irrigation (Salmon et al., 2015). According to the Köppen-Geiger climate classification this area can be ascribed to the Cfa class (temperate climate, without dry season and with hot summers). The simulation area (red box on Figure 1b-c) is mainly characterized by croplands, except the south, south-western area where forests and more complex topography are dominant. This pilot site has an extension of $1800 \mathrm{~km}^{2}$; it is located in the Emilia Romagna region and is characterized by one of the most 
technologically advanced Italian irrigation hydraulic system - the Canale Emiliano Romagnolo (CER, https://consorziocer.it/it/, last access 27 November 2021). In recent years, this area was affected by frequent water scarcity periods (Ceppi et al., 2014; Strosser et al., 2012), which have increased the need for optimal water management. In situ data, used for evaluation, were collected over the test site of Budrio (Figure 1b) and Faenza (Figure 1c). In particular, the Budrio farm is managed by CER and includes five small fields extended for 0.4 ha each. The most common crop types are tomatoes and maize and daily irrigation data are available for the period 2015-2016 for four out of the five fields and for the year 2017 for the last plot. The second Italian test site is located around the city of Faenza, consisting of two small-districts: San Silvestro (hereafter Faenza F1) which has an extension of 290 ha, and Formellino (Faenza F2 hereafter), reaching 760 ha. The crops growing on the Faenza small-districts are pear and kiwi which typically require a significant amount of water. The water used for irrigation at daily time scale was provided by CER for the two years 2016-2017. Daily rainfall data are collected from the national rainfall network managed by the Department of Civil and Environmental Protection (DPC) of Italy, for the irrigated periods.

\subsection{Remote sensing observations}

The European Space Agency (ESA) and Copernicus Sentinel-1 mission collects active microwave backscatter data at C-band $(5.4 \mathrm{GHz})$ at a high spatial $(\sim 20 \mathrm{~m})$ and temporal (less than weekly) resolution in Interferometric Wide (IW) swath mode. The processing of the ground-range detected (GRD) backscatter observations in VV-and VH-polarization was done using the ESA

145 Sentinel Application Platform (SNAP) software and included standard techniques: precise orbit file application, border noise removal, thermal noise removal, radiometric calibration to backscatter as beta-nought, terrain flattening to backscatter as gamma-nought ( $\gamma^{0}$ hereafter), and range-Doppler terrain correction. Furthermore, the $\gamma^{0}$ observations, originally acquired at $\sim 20 \mathrm{~m}$ spatial resolution, were aggregated by multilooking, masked for urban area and water bodies, and projected on the $0.01^{\circ}$ latitude-longitude grid as used in LIS Noah-MP LSM. After applying an orbit bias-correction (Lievens et al., 2019), the observations from different orbits, either from Sentinel-1A or -1B and ascending or descending tracks, were combined at the daily time-scale, with a mean temporal resolution of one assimilated observation every $\sim 3$ days over the pilot sites. Additional RS observations were used for the evaluation of Noah-MP LSM simulations:

- The Metop ASCAT surface soil moisture (SSM) Climate Data Records H115 and its extension H116 are provided by the European Organization for the Exploitation of Meteorological Satellites (EUMETSAT) Support to Operational Hydrology and Water Management (H SAF; http://hsaf.meteoam.it/, last access 20 May 2021). The SSM retrieval is characterized by a spatial sampling of $12.5 \mathrm{~km}$ and a temporal resolution of one to two observations per day, depending on the latitude.

- The PROBA-V leaf area index (LAI) is provided by the Copernicus Global Land Service programme (CGLS, https://land.copernicus.eu/global/). The CGLS product at $1 \mathrm{~km}$ spatial resolution and 10-day temporal resolution is developed based on the work by Verger et al. (2014). 
- The Moderate Resolution Imaging Spectroradiometer (MODIS) is a multispectral sensor on-board TERRA and AQUA satellites acquiring image data of the Earth's surface simultaneously in visible/infra-red bands. For this work the MOD16A2 Version 6 Evapotranspiration product was used for evaluation. This is an 8-day composite product characterized by 500 -meter spatial resolution.

165 ASCAT SSM, PROBA-V LAI and MODIS ET were extracted over the test sites and re-gridded over the LIS grid spatial domain $\left(0.01^{\circ}\right)$ as well as sampled to a daily time scale in order to match the LIS outputs.

\subsection{Land surface and irrigation modelling}

The LSM selected for this study is the Noah-MP.v.3.6 (Niu et al., 2011). This model is able to dynamically simulate vegetation and soil moisture in 4 layers, i.e., 0-10, 10-40, 40-100 and 100-200 cm depth. For this study, the Noah-MP model was coupled to a sprinkler irrigation module (Ozdogan et al., 2010a) embedded within the NASA's LIS version 7.3 (Kumar et al., 2008 ). For a more detailed description of the Noah-MP parameterization used in this study the reader can refer to Modanesi et al. (2021).

The irrigation module adds water as pseudo-precipitation to mimic sprinkler systems (Ozdogan et al., 2010a), and does not further change processes related to e.g., vapor fluxes (which would be needed for highly efficient drip irrigation systems;

175 Evans and Zaitchik, 2008). In order to identify the timing and location of irrigation, four conditions need to be met: (i) irrigable land cover (i.e., croplands), (ii) irrigated land fraction, (iii) growing season and (iv) dry enough root-zone soil moisture. The first two conditions are tested against static land cover (LC) and irrigation intensity (areal fraction) maps. The growing season was defined based on a user-defined threshold of simulated LAI (LAI>1). The LAI value is then converted to the greenness vegetation fraction (GVF) in accordance with Fang et al. (2018):

$$
G V F=1-e^{-b * L A I}
$$

where b [-] is an empirical parameter that depends on plant canopy (Fang et al., 2018; Norman et al., 1995). Finally, the irrigation is applied when the root-zone soil moisture availability falls below a user-defined threshold, which has been set to $50 \%$ of field capacity (FC) as in Ozdogan et al. (2010a) for the German pilot site and 45\% in Italy (a previous analysis has shown large overestimations using a threshold of 50\% in the Po Valley). The irrigation amount is determined by the amount of water needed to increase the root-zone soil moisture back to FC. In this context, the maximum rooting depth is an important input parameter, impacting the frequency of irrigation events as well as the amount of irrigated water.

The modelled irrigation estimates are thus primarily controlled by five datasets: static LC, irrigation fraction, soil texture, crop type, and dynamic meteorological forcing. In this study, the static 1-km LC is derived from the CGLS $100 \mathrm{~m}$ global LC map for the year 2015 (Buchhorn et al., 2020; available at https://land.copernicus.eu/global/products/lc , last access 21 December

190 2021). The 23 classes of this global LC map were reclassified to the 14 classes supported by LIS and re-gridded to $0.01^{\circ}$ (for additional details on the reclassification the reader can refer to Modanesi et al., 2021). The global 500-m rain-fed, irrigated, 
and paddy croplands dataset (GRIPC) by Salmon et al. (2015) is used to map the irrigation fractional area. However, the GRIPC input lacks important information over the German test site, which is classified as non-irrigated. In order to allow irrigation simulations over Germany, the irrigation fractional area was set to $100 \%$ over the known irrigated LIS grid pixels (based on irrigation benchmark data). The parameters needed to activate the irrigation scheme are summarized in Table 1 .

Table 1: Parameters needed to activate the irrigation scheme in Noah-MP, based on the two pilot sites.

\begin{tabular}{|l|l|l|l|l|l|}
\hline Pilot Site & $\begin{array}{l}\text { Noah-MP } \\
\text { LAI [-] }\end{array}$ & $\begin{array}{l}\text { Crop rooting } \\
\text { depth [m] }\end{array}$ & $\begin{array}{l}\text { Irrigation } \\
\text { fraction }\end{array}$ & $\begin{array}{l}\text { Land use } \\
\text { threshold [\%] }\end{array}$ \\
\hline Italy & $>1$ & 1 & GRIPC & Cropland & 45 \\
\hline Germany & $>1$ & 0.8 & User-defined & Cropland & 50 \\
\hline
\end{tabular}

Soil texture and the associated parameters were extracted from the 1-km Harmonized Soil World Database (HWSD v1.21) and mapped to discrete soil classes with their associated soil hydraulic parameters as in Modanesi et al. (2021). Given the lack of European or large-scale dynamic crop map datasets, the crop type was set to a generic type with a maximum rooting depth of $1 \mathrm{~m}$ in Italy (Modanesi et al., 2021) and $0.8 \mathrm{~m}$ Germany. In particular, in the Niedersachsen test site, an averaged rooting depth was calculated based on the main crop types cultivated at the irrigated fields.

The dynamic meteorological forcing data were extracted from Modern-Era Retrospective analysis for Research and Applications, version 2 (MERRA-2; Gelaro et al., 2017), which is not corrected for surface or screen-level observations (and are thus unlikely to contain feedback from -unmodelled and unobserved-irrigation). The meteorological data, at original spatial resolution of $0.5^{\circ} \times 0.625^{\circ}$, were remapped to $0.01^{\circ}$ spatial resolution via bilinear interpolation.

\subsection{Observation operator and calibration}

The observation operator used to ingest Sentinel-1 $\gamma^{0}$ observations into the Noah-MP LSM is represented by the Water Cloud Model (WCM) introduced by Attema and Ulaby (1978). The WCM simulates the total $\gamma^{0}$ as the sum of the $\gamma^{0}$ from the vegetation $\left(\gamma^{0}{ }_{v e g}\right)$ and the $\gamma^{0}$ from the soil $\left(\gamma^{0}\right.$ soil $)$ attenuated by the vegetation $\left(t^{2}\right)$ as follows:

$$
\gamma_{\text {tot }}^{0}=\gamma_{v e g}^{0}+t^{2} \gamma_{\text {soil }}^{0}
$$

For more information on the WCM the reader can refer to Lievens et al., (2017a) and Modanesi et al. (2021). The WCM includes four fitting parameters, two of them related to the scattering and attenuation by vegetation and the other two parameters to model the soil backscatter contribution as a linear function of the SSM. Those parameters were calibrated to limit long-term biases between Sentinel-1 observations, which include an irrigation signal over irrigated areas, and the LSM simulations. The WCM calibration was performed for each individual grid cell using the procedure designed in Modanesi et 
al. (2021) which includes: i) the use of Noah-MP SSM and LAI as inputs for the WCM (ensemble mean time series from an open loop simulation); ii) the use of Sentinel- $1 \gamma^{0} \mathrm{VV}$ and VH separately to tune the parameters for the simulation of $\gamma^{0} \mathrm{VV}$ and VH independently; iii) the activation of the irrigation scheme to reduce seasonal inconsistencies between simulated and observed $\gamma^{0}$ during irrigation periods; iv) the optimization of a Bayesian objective function represented by the Sum of Square Error between $\gamma^{0}$ observations and simulations, and a constraint on prior parameter estimates, using the DiffeRential Evolution Adaptive Metropolis (DREAM(ZS); Vrugt et al., 2008 De Lannoy et al. 2014). The calibration was realized for the period January 2018-December 2020.

\subsection{Data assimilation}

The DA system was developed in order to directly assimilate Sentinel-1 $\gamma^{0}$ observations into Noah-MP and sequentially update both soil moisture and vegetation within the LIS framework. The direct assimilation of $\gamma^{0}$ observations requires that simulated land surface state variables are first mapped to $\gamma^{0}$ predictions (forecast) via a second modelling step, i.e., via the WCM as observation operator (Section 2.4). The assimilation was performed via an ensemble Kalman filter (EnKF; Evensen, 2003, 1994) which updates the land surface state, where and when satellite-based $\gamma^{0}$ observations are available. Specifically, a 1dimensional EnKF was applied (Reichle et al., 2002), using Sentinel-1 observations at the same spatial grid as that of the model simulations. In this study, the updated land surface state variables during the assimilation include both surface soil moisture $(0-10 \mathrm{~cm})$ and LAI, and the deeper profile layers are also updated (10-40, 40-100 and 100-200 cm) via error cross correlations. All other fluxes and state variables, including irrigation estimates, are consistently adjusted via model propagation.

The EnKF assumes unbiased observations and forecasts. This is achieved by running the Noah-MP with a poor guess of irrigation activated and using calibrated WCM parameters to produce unbiased $\gamma^{0}$ forecasts relative to Sentinel-1 $\gamma^{0}$ (which 'senses' irrigation). The optimality of the Kalman filter further strongly depends on the characterization of the random component of forecast and observation errors. In this context, the forecast errors are diagnosed from an ensemble of 24 land model (including WCM) trajectories from which the error covariances are estimated at the time of an update. The ensembles are generated by perturbing selected meteorological input forcings (i.e., rainfall, incidence longwave and shortwave radiations) and state variables. The perturbation parameters, summarized in Table 2, are based on Kumar et al. (2014) aiming at a unit standard deviation of normalized $\gamma^{0}$ innovations (De Lannoy and Reichle, 2016; Reichle et al., 2017). Only the SSM and LAI state variables are perturbed and no temporal autocorrelation is used to avoid excessive uncertainty estimates. The observation error standard deviation is set to $1 \mathrm{~dB}$, regardless of the polarization or orbit of the $\gamma^{0}$ observations.

The main equation of the EnKF can then be written as follows:

$$
\widehat{x_{l}^{+}}=\widehat{x_{l}^{-}}+K_{i}\left[y_{o b s, i}-h_{i}\left(\widehat{x_{l}^{-}}\right)\right](6)
$$

where $i$ represents the time step, $\widehat{x_{l}^{+}}$is an ensemble of model states after assimilation and $\widehat{x_{l}^{-}}$represents the forecast ensemble state (i.e., SSM and LAI), $y_{o b s, i}$ are the assimilated observations at time $i$ and $h_{i}($.$) is the WCM observation operator. The$ 
term $y_{o b s, i}-h_{i}\left(\widehat{x_{l}^{-}}\right)$is the $\gamma^{0}$ observation-minus-forecast $(\mathrm{O}-\mathrm{F})$ residual in $\mathrm{dB}$, and is mapped to updates in the model state via de Kalman gain $K_{i}$ described as follows:

$$
K_{i}=\left[C_{Y M}\left(C_{M}+C_{v}\right)^{-1}\right]_{i}(7)
$$

In Equation (7) $C_{Y M, i}$ is the error cross covariance matrix between the state and observation predictions, $C_{M, i}$ is the forecast error covariance matrix of the backscatter (observation) predictions.

The above method will update forecasted irrigation estimates by correcting random errors in land surface state forecasts. An alternative method would be to run the Noah-MP without irrigation activated and to derive irrigation estimates from the amount of water or vegetation added to the system via DA (i.e., the increments), if the true precipitation is used as input and if the observation operator is also not compensating for irrigation. More specifically, positive and autocorrelated increments in the growing season would be indicative of irrigation. However, this would also be indicative of a suboptimal assimilation system. In this study, we use imperfect reanalysis precipitation input and we simulate irrigation through an irrigation scheme. Increments of any sign could thus be related to over- or underestimation of irrigation.

Table 2: Perturbation parameters for forcing (i.e., rainfall, incident and shortwave radiation) and state variables (i.e., SSM and LAI)

\begin{tabular}{|c|c|c|}
\hline Variable & Perturbation type & $\begin{array}{c}\text { Standard } \\
\text { deviation }\end{array}$ \\
\hline Rainfall $\left[\mathrm{kg} / \mathrm{m}^{2} \mathrm{~s}\right]$ & Multiplicative & 0.5 \\
\hline Incident longwave radiation [W/m2] & Additive & 50.0 \\
\hline Incident shortwave radiation $[\mathrm{W} / \mathrm{m} 2]$ & Multiplicative & 0.3 \\
\hline $\mathrm{SSM}\left[\mathrm{m}^{3} / \mathrm{m}^{3}\right]$ & Additive & 0.012 \\
\hline $\mathrm{LAI}[-]$ & Additive & 0.04 \\
\hline
\end{tabular}

\subsection{Experiments}

In this study we considered two different experimental lines: i) the assimilation of Sentinel-1 $\gamma^{0} \mathrm{VV}$ (Sentinel-1 $\gamma^{0} V V$ DA hereafter), and ii) the assimilation of Sentinel-1 $\gamma^{0} \mathrm{VH}$ (Sentinel-1 $\gamma^{0} \mathrm{VH}$ DA hereafter), both to sequentially update SSM and LAI. The experimental workflow is described in the scheme of Figure 2.

270 For each pilot site, the Noah-MP model was previously spun-up from January 1982 to May 2014. Then, an ensemble spin-up was realized in Open Loop (OL) mode using 24 ensemble members from May 2014 to January 2015, in order to obtain optimal 
initial conditions. The OL run was continued thereafter from January 2015 onwards through December 2020. Similarly, the Sentinel- $1 \gamma^{0}$ VV DA and Sentinel-1 $\gamma^{0}$ VH DA experiments were run from January 2015 through December 2020.

\subsection{Evaluation}

275 The evaluation aimed at: i) verifying the goodness of the DA system in terms of DA diagnostics; ii) highlighting benefits of the Sentinel-1 DA for irrigation, soil moisture and LAI estimation as well as testing the differences between the Sentinel-1 $\gamma^{0}$ VV DA and the Sentinel-1 $\gamma^{0}$ VH DA configurations; iii) verifying the influence of the spatial scale of the test sites on the irrigation simulation and evaluation; and iv) identifying shortcomings of the system.

To achieve those targets, two types of evaluation were carried out:

- The optimality of the DA system design was evaluated regionally for each pilot site, for the period January 2015December 2020. Following Reichle et al. (2017), three different filter diagnostics were analysed. First, the difference between the temporal mean ensemble standard deviation (or ensemble spread) of the DA and OL runs was computed to test whether the DA system successfully reduces the uncertainties (i.e., ensemble spread) as compared to the OL run. Second, the time-series standard deviation of the normalized $\gamma^{0} \mathrm{O}-\mathrm{F}$ residuals was computed to check if observation and model errors were adequately chosen. In ideal conditions this metric should be equal to unity over the entire study area. The normalized O-F residuals were obtained by normalizing each O-F residual by their simulated (expected) (forecast and observation error) standard deviation and then calculating the time-series standard deviation (Bechtold et al., 2020; Reichle et al., 2019). Third, the time-series standard deviations of the increments (analysis forecast) in SSM and LAI were investigated in order to verify whether those values are small relative to the values of the update state variables.

- The OL and DA estimates of irrigation, SSM, LAI and ET were evaluated using independent reference data for the years 2015-2017 and 2016-2017 at the Budrio and Faenza (Italian) sites and for the year 2018 at the German sites. The evaluation of ensemble mean irrigation simulations was assessed in terms of correlation and percentage bias (Pearson-R and bias hereafter) between estimated irrigation volumes and benchmark irrigation data. As the irrigation timing is often driven by stakeholders' turns to withdraw water and by water availability rather than by the root-zone moisture conditions, and because short-term DA increments influence short-term activations of the irrigation system, the comparisons between simulations and in-situ observations were carried out by accumulating irrigation data at biweekly time window. An evaluation of daily SSM and LAI outputs was performed against ASCAT SSM and PROBAV LAI, respectively, in terms of Pearson-R. The ET outputs were tested against MODIS ET, considering the important role that irrigation has in affecting ET (Haddeland et al., 2014; Lawston et al., 2015). The latter however, must be considered more a comparison than a real validation given the inherent uncertainties contained in the MODIS ET product.

The evaluation of the $0.01^{\circ}$ irrigation simulations with benchmark data asks for careful data handling and offers opportunities to relate skill metrics to properties of the irrigated regions. First, the Italian pilot site is composed of 
Budrio with five small fields of 0.4 ha within one LIS grid cell $\left(0.01^{\circ}\right)$, the Faenza F1 test site of 290 ha, covering three LIS grid cells, and Faenza F2 of 760 ha including eight LIS grid cells. The benchmark irrigation data for the five fields in Budrio were averaged to obtain a unique time series, whereas at the Faenza test sites the LIS simulations were averaged to obtain a single time-series for each field (and for each analysed variable). This allows to relate skill metrics to the spatial scale (one pixel at Budrio, to district scale at Faenza) of simulations and reference data. Second, the German pilot site is composed of 49 fields, covering 24 LIS pixels. By considering only pixels with a percentage of irrigated area larger than $25 \%, 8$ irrigated pixels of the 24 pixels were retained. For these 8 pixels, statistical distributions of the skill metrics could be obtained.

\section{RESULTS}

\subsection{Data assimilation diagnostics}

315 The two DA experiments (Sentinel-1 $\gamma^{0}$ VV DA and Sentinel-1 $\gamma^{0}$ VH DA) were evaluated in terms of DA optimality and increments, over the period January 2015-December 2020 for both Germany and Italy. Figure 3 shows a general reduction in the time-mean ensemble spread in SSM or LAI due to DA compared to the spread of the OL runs $(\Delta$ SSM Ens. Spread mean; $\Delta$ LAI Ens. Spread mean), for both the Sentinel-1 $\gamma^{0} \mathrm{VV}$ and VH DA experiments. In Italy (Figures $3 \mathrm{a}$, c, e and g) a larger reduction of the ensemble SSM and LAI spread is identified over croplands and particularly over the western, north-western part of the study area where a higher number of observations is assimilated (maps representing the number of assimilated observations for each experiment and each test site are displayed in Figure S3 of the Supplementary). The patches with a lower spread reduction are associated to input soil parameters and in particular to the presence of silty-loam soil texture which contrasts the sandy-loam soil of the remaining area (LIS input is shown in Figure S1). The two texture classes lead to very different soil moisture time series. In a previous study (Modanesi et al., 2021), a lower agreement of calibrated WCM simulations with Sentinel-1 observations was found over the silty-loam soil texture, and this reflects in the lower reduction of SSM spread when assimilating Sentinel-1 (Figures 3a and 3c). These features are much less visible in the difference of LAI spreads (LAI is mainly associated with the almost homogenous vegetation class, not so much with texture). Furthermore, the Sentinel-1 $\gamma^{0}$ VH DA displays larger spread reduction in terms of LAI over croplands compared to the Sentinel-1 $\gamma^{0}$ VV DA experiment, showing a large influence of the vegetation in the $\gamma^{0} \mathrm{VH}$ signal. For Germany the results show a similar link between the soil texture and the SSM spread reduction, especially for the Sentinel-1 $\gamma^{0}$ VV DA experiment (Figure $3 b$ ) where pixels with a stronger spread reduction are associated to sandy-loam soil texture (LIS input is shown in Figure S2 for Germany). The absolute mean decrease in spread $(m)$ over Germany is less pronounced than for the Italian pilot site (e.g., for Sentinel-1 $\gamma^{0}$ VH DA, $\Delta$ LAI Ens. Spread mean $m=-0.1$ for Italy and $m=-0.05$ for Germany), which is partly due to the state-dependency of the spread (e.g., higher LAI values and larger spreads in Italy than in Germany).

335 Figure 4 shows the standard deviation of the normalized O-F residuals time series, for both the Sentinel-1 $\gamma^{0}$ VV DA and Sentinel-1 $\gamma^{0}$ VH DA. In an optimal DA system these values should be equal to 1 over the entire study area for an agreement 
between the actual and simulated (expected) forecast and the observation errors. In Italy, $m=0.83$ and $m=0.82$ are obtained for the Sentinel-1 $\gamma^{0}$ VV DA and the Sentinel-1 $\gamma^{0}$ VH DA experiments respectively but, once again, the spatial patterns are consistent with the soil texture distribution. The large ellipsoid feature, in the northern side of the study area, is characterized by values exceeding the unity, meaning that the sum of observation and forecast error, prescribed in the ensemble perturbation, underestimates the actual errors. Similarly, in Germany we obtain near-optimal results in terms of $m$ values over the entire study area but larger error underestimations are observed over the silty-loam soil texture, with values larger than 1.5 for both DA experiments (Figures $4 \mathrm{~b}$ and $4 \mathrm{~d}$ ). In Germany an additional source of uncertainty is related to the irrigation fraction information, which is zero over the entire cropland area, except for the pixels for which we collected irrigation benchmark data (see discussion on GRIPC input, Section 2.3). We hypothesize that the lack of accurate information on the irrigated fraction over other pixels can negatively affect the WCM calibration and indeed the results in terms of DA diagnostics.

Finally, we analysed the increments of SSM and LAI over the study area. In a well calibrated DA system, the long-term mean of the increments is expected to be close to zero at each pixel. As explained in Reichle et al. (2019), values close to zero indicate that no long-term net addition or subtraction of water (or vegetation) is generated by the analysis. As expected, the temporal mean values of SSM and LAI analysis increments vanish in the regional average (results not shown). However, the standard deviation of the analysis increments provides valuable information which has been summarized in Figure 5. Maps of SSM (Figure 5a-d) and LAI (Figure 5e-h) show generally small increment standard deviations for both DA experiments and both study areas. Note that zero standard deviations are found where no data were assimilated (see Figure S3). For both areas, complementary patterns are observed for SSM and LAI increments. Larger SSM variances can be observed over the cropland area characterized by sandy soil (e.g., north-west in Italy) and where a higher number of observations are assimilated (especially in Italy), whereas larger LAI updates are related to the silty-loam soil type (e.g., ellipsoid-shaped area in Italy), corresponding to the patterns in O-F (not shown, but the pattern of standard deviations of normalized O-F in Figure 4 is similar to that of O-F). This is particularly true for the Sentinel- $1 \gamma^{0}$ VH DA experiment.

Although the DA diagnostics show satisfactory results in terms of consistency of the system, input parameters, such as soil texture and vegetation (i.e., lack of dynamic crop maps in the model) seem to have a strong impact on the performance of the DA system. In this context, the red squares in Figure 4a-b and Figure 5a-b show areas where the test sites are located. In Italy (Figure 4a or Figure 5a) the Budrio test site (north-west square) is placed over an area where results are close to optimal in terms of standard deviation of normalized O-F. On the other hand, the Faenza test site shows a certain overestimation of the actual observation error (south-east square in Figure 4a). In any case, although influences related to the mentioned input data are present, overall, the results are acceptable and near-optimal over both the Italian and German test sites.

\subsection{SSM, LAI, ET and irrigation evaluation: DA vs OL}

In this section we show the results of the DA and OL runs in terms of irrigation, SSM, LAI and ET. We first discuss the Italian pilot site, where the longest record (2-3 year) of benchmark data is available for 3 test sites with different spatial extents. This allows us to focus on the impact of the spatial scale on the performance of the DA system. Next, we discuss the pilot site in 
Germany where the availability of 1 year of data for 49 small irrigated fields (24 LIS pixels, of which only 8 were retained considering a percentage of irrigated area larger than 25\%) allows for a statistical interpretation of the results.

\subsubsection{Italy}

Figure 6 shows an example time series of SSM, LAI, ET and irrigation at the Budrio farm for the OL and Sentinel-1 $\gamma^{0}$ VV DA experiment, including a comparison in terms of $\gamma^{0}$ observations and forecasts. Also shown are the reference data of ASCAT

SSM, PROBA-V LAI and MODIS ET observations at daily time scale. For irrigation, the benchmark reference data, OL and DA output are aggregated to a bi-weekly time scale.

The irrigation simulations (Figure 6e) show a general deterioration of the performance with DA, with a decrease in Pearson$\mathrm{R}$ from $0.78(\mathrm{OL})$ to 0.65 (DA). However, the DA run provides better results in terms of irrigation quantities, with accumulated benchmark irrigation equal to $917.2 \mathrm{~mm}$ against the $842.5 \mathrm{~mm}$ of the DA run (as compared to the large overestimation provided by the OL run with $1220.1 \mathrm{~mm}$ ). Figure 6e additionally shows the time series of rainfall from rain-gauge observations and MERRA-2 forcing (upper axes). Although a good agreement is observed between MERRA-2 and gauge-rainfall in terms of Pearson-R (0.78), it is worth noting that the precipitation from MERRA-2 during the summer is typically less than in situ rainfall and this aspect could also contribute to create underestimations in irrigation simulation, which is partly corrected by the Sentinel-1 $\gamma^{0}$ VV DA.

385 Figure $6 \mathrm{~b}$ shows the impact of DA in the SSM dynamics during both the summer and winter seasons. The Sentinel-1 $\gamma^{0}$ corrects a dry winter bias that is observed in the OL run SSM time-series, while during the summer the increments affect mainly the short-term dynamics. The LAI time-series are less affected by the ingestion of Sentinel-1 during the growing season (Figure 6c) than SSM. The larger updates in terms of SSM are also reflected in a larger improvement in terms of Pearson-R for SSM as compared to LAI: for SSM, the Pearson-R increases from 0.74 for the OL to 0.78 for the DA, while for LAI (Figure $6 \mathrm{c}$ ) the increase in Pearson- $\mathrm{R}$ is smaller (from 0.69 to 0.71 ). This is also explained by the results shown in Figure 6a where the daily WCM $\gamma^{0}$ VV forecast time-series are compared with Sentinel-1 observations: it is worth noting that the soil contribution in both the simulated and observed $\gamma^{0}$ signal is much higher than the vegetation contribution, confirming what was highlighted in previous studies (i.e., Bauer-Marschallinger et al., 2018; Modanesi et al., 2021; Wagner et al., 2013). By design, the DA run provides better agreement (Pearson-R=0.81) between the WCM forecasts and Sentinel-1 observations than the OL run 395 (Pearson- $\mathrm{R}=0.67$ ).

When comparing the ET results against MODIS ET, a slight improvement is observed when DA is performed (Figure 6d; Pearson-R increases from 0.69 to 0.72 ), and a general overestimation in the model outputs was observed for both the OL and DA runs over the late summer months (from July to October of each year). The general decrease of MODIS ET during the late summer is not explained by the irrigation benchmark time series reported in Figure 6e, and shows a dubious response to irrigation events. This highlights possible uncertainties related to reference ET observations or benchmark irrigation data, and we believe that in this case the ET estimates are the least reliable. 
Additional time series analyses for the other Italian sites and for $\gamma^{0}$ VH DA are reported in the Supplementary material (Figures S4 through S6).

Table 3: Evaluation results at all the italian test sites and for both the DA experiments.

\begin{tabular}{|c|c|c|c|c|c|c|c|c|}
\hline \multirow{2}{*}{$\begin{array}{l}\text { ITALY } \\
\text { TEST } \\
\text { SITES }\end{array}$} & \multirow{2}{*}{\begin{tabular}{ll}
\multicolumn{2}{l}{ Benchmark } \\
period \& \\
number of \\
LIS pixel
\end{tabular}} & \multirow[t]{2}{*}{ Model run } & \multicolumn{6}{|c|}{ SCORE } \\
\hline & & & $\begin{array}{l}\text { SSM } \\
\text { Pearson-R } \\
{[-]}\end{array}$ & $\begin{array}{l}\text { LAI } \\
\text { Pearson-R } \\
{[-]}\end{array}$ & $\begin{array}{l}\text { ET } \\
\text { Pearson-R } \\
{[-]}\end{array}$ & $\begin{array}{l}\text { Irr. } \\
\text { Pearson-R } \\
{[-]}\end{array}$ & $\begin{array}{l}\text { Irr. } \\
\text { Bias } \\
{[\%]}\end{array}$ & $\begin{array}{l}\text { Irr. } \\
\text { Amoun } \\
{[\mathrm{mm}]}\end{array}$ \\
\hline \multirow[t]{5}{*}{ Budrio } & \multirow{5}{*}{$\begin{array}{l}2015-2017 \\
1 \text { pixel }\end{array}$} & OL VV & 0.74 & 0.69 & 0.70 & 0.78 & 33.0 & 1220.1 \\
\hline & & DA VV & 0.78 & 0.71 & 0.71 & 0.65 & -8.1 & 842.5 \\
\hline & & OL VH & 0.74 & 0.69 & 0.70 & 0.79 & 33.0 & 1220.0 \\
\hline & & DA VH & 0.76 & 0.72 & 0.72 & 0.55 & -20.6 & 728.1 \\
\hline & & Benchmark & I & l & I & I & l & 917.2 \\
\hline \multirow{5}{*}{$\begin{array}{l}\text { Faenza } \\
\text { F1 }\end{array}$} & \multirow{5}{*}{$\begin{array}{l}2016-2017 \\
3 \text { pixels }\end{array}$} & OL VV & 0.78 & 0.73 & 0.65 & 0.90 & 121.9 & 753.6 \\
\hline & & DA VV & 0.81 & 0.74 & 0.66 & 0.75 & 54.4 & 524.1 \\
\hline & & OL VH & 0.78 & 0.73 & 0.65 & 0.90 & 121.9 & 753.6 \\
\hline & & DA VH & 0.79 & 0.76 & 0.67 & 0.64 & 26.3 & 428.9 \\
\hline & & Benchmark & I & I & I & I & l & 339.5 \\
\hline \multirow{5}{*}{$\begin{array}{l}\text { Faenza } \\
\text { F2 }\end{array}$} & \multirow{5}{*}{$\begin{array}{l}2016-2017 \\
8 \text { pixels }\end{array}$} & OL VV & 0.78 & 0.86 & 0.79 & 0.88 & 115.2 & 751.0 \\
\hline & & DA VV & 0.80 & 0.86 & 0.80 & 0.86 & 83.6 & 641.0 \\
\hline & & OL VH & 0.78 & 0.86 & 0.79 & 0.88 & 115.2 & 751.0 \\
\hline & & DA VH & 0.79 & 0.87 & 0.81 & 0.80 & 51.3 & 528.0 \\
\hline & & Benchmark & 1 & 1 & I & 1 & I & 349.0 \\
\hline
\end{tabular}

Table 3 summarizes the results obtained for the 3 test sites within the Italian pilot site. For the Faenza sites, the results are first spatially aggregated over 3 or 8 pixels before computing time series metrics. The uncertainty in the reference data and the relatively short data records prevent a statistically significant evaluation, but overall, the DA runs provide a slight improvement of SSM and LAI for both the DA experiments compared to the OL run. As expected, Sentinel- $1 \gamma^{0}$ VV DA provides better results in terms of SSM temporal dynamics while the Sentinel-1 $\gamma^{0}$ VH DA shows larger improvements for LAI and ET. These findings confirm that $\gamma^{0}$ VV contains more information about SSM (Bauer-Marschallinger et al., 2018; Modanesi et al., 2021; Wagner et al., 2013), whereas $\gamma^{0}$ VH seems to be more related to vegetation (LAI) (i.e., Macelloni et al., 2001; Vreugdenhil et al., 2018). Due to the effect of LAI and SSM on plants transpiration, ET is also minimally improved. In terms of irrigation 
https://doi.org/10.5194/hess-2022-61

Hydrology and

Preprint. Discussion started: 2 March 2022

(c) Author(s) 2022. CC BY 4.0 License.

temporal dynamics, the DA experiments slightly deteriorate the temporal dynamics for all the test sites but reduce the bias in

the irrigation estimates.

Figure 7 summarizes the Pearson-R and bias scores for the irrigation simulations for all the experiments, and for the 3 Italian test sites. Even though DA always reduces the R-values compared to those of the OL, Figures 7a and 7c suggest that the Rvalues for the DA experiments increase when moving from the small area of Budrio (1 LIS pixel) to Faenza F2 (8 LIS pixels), and that the skill reduction introduced by DA is only marginal for the largest Faenza F2 field. An explanation could be related to the spatial mismatch between the 1-km Sentinel-1 signal and the small Budrio fields ( 2 ha in total) together with to the poor model ability to reproduce stakeholder's decisions (i.e., irrigation timing) in areas extended over few ha, such as in Budrio.

Even though DA deteriorates the irrigation results in terms of R, it improves the results in percentage bias (Figures $7 \mathrm{~b}$ and $7 \mathrm{~d}$ ). In general, the Noah-MP LSM overestimates irrigation over all the test sites in the OL run. Here, the Sentinel-1 $\gamma^{0}$ VH DA provides more reliable irrigation quantities. We hypothesize this could be attributed to the ability of the Sentinel-1 $\gamma^{0} \mathrm{VH}$ to introduce stronger updates in LAI, which is more linked to root-zone soil moisture under well-developed crops than SSM (Modanesi et al. 2021). Results in terms of bias show another important aspect: although many limitations in the simulation of the irrigation dynamics are related to the spatial scale, the quality of the benchmark irrigation data also has an important impact. For a small site such as Budrio, irrigation benchmark is expected to be more precise, explaining lower biases in terms of 430 irrigation quantities.

\subsubsection{Germany}

In the Niedersachsen test site, the analysis was conducted over 8 LIS pixels based on the pre-processing described at Section 2.7. The evaluation in terms of SSM and LAI using ASCAT SSM and PROBA-V LAI (not shown) does not display substantial differences in terms of Pearson-R between the OL and the DA runs (median Pearson-R equal to $\sim 0.8$ for SSM and $\sim 0.7$ for

435 LAI, across 8 pixels). Regarding irrigation estimates, Figures 8a and 8b display the Pearson-R and percentage bias distributions over the 8 selected irrigated pixels for the OL and the Sentinel-1 $\gamma^{0}$ VV DA experiment, while Figures 8c and 8d refer to the Sentinel-1 $\gamma^{0}$ VH DA. In particular, Figure 8a and 8c show improved irrigation estimates for both Sentinel-1 $\gamma^{0}$ VV DA (Pearson-R increases from 0.47 to 0.61 ) and Sentinel-1 $\gamma^{0}$ VH DA (Pearson-R increases from 0.47 to 0.65).

Unlike the Italian site, the Niedersachsen site suffers from an irrigation underestimation by the model, in line with a previous 440 study by Zappa et al. (2021) which used Sentinel-1 SSM retrievals to detect and quantify irrigation at the Niedersachsen test site. Figure $8 \mathrm{~b}$ shows that the median bias is reduced from a value of $-40.8 \%$ for the OL to a value of $-24.6 \%$ for Sentinel- $1 \gamma^{0} \mathrm{VV}$ DA and Figure $8 d$ shows a reduction from $-40.8 \%$ for OL to $-7.6 \%$ for Sentinel- $1 \gamma^{0}$ VH DA. Despite the improvement in median values for the bias, the overall distribution of the bias is wider than for the OL. Reasons for that might be related to the specificity of the different fields and the difference in the performance for different spatial scales (see section 3.2.1) when 445 different fields of different size are bulked altogether. Beyond this, also the consistency between simulated backscatter by the coupled Noah-MP-WCM and Sentinel-1 data for some specific pixels might exert a role in spreading the distribution of the 
bias with respect to the OL. The latter can be caused by both poor model performance (due to the quality of the forcing, model parameters and static maps) and the quality of the Sentinel-1 $\gamma^{0}$ data.

\section{DISCUSSION}

\subsection{Data assimilation}

In this study, we built a DA system for the ingestion of Sentinel-1 $\gamma^{0}$ both in VV and VH polarization into the Noah-MP LSM in order to test the ability of Sentinel- $1 \gamma^{0}$ to improve irrigation quantification through the update of both SSM and LAI. The regional scale analysis of internal DA diagnostics provided evidence that the DA system is self-consistent and near-optimal. Local deviations from desirable reductions in ensemble spread or from optimal O-F statistics, or higher absolute SSM or LAI increments were mainly related to poor input data to the Noah-MP LSM. Confirming what was previously found in Modanesi et al. (2021), soil texture uncertainties play an important role in reducing (or increasing) the effectiveness of the DA system. This is because the soil texture affects the root-zone soil moisture and FC, which contribute to the activation of the irrigation scheme. The silty-loam soil texture generally shows a reduced variability in the soil moisture dynamics as compared to more sandy textures, providing lower amount of irrigation, especially over wetter climates (i.e., Germany). Assuming that the Sentinel-1 $\gamma^{0}$ contains information on irrigation, the DA system should correct poorly simulated irrigation, e.g., due to poor input parameterization or errors in MERRA-2 precipitation input as compared to in situ precipitation (which was observed in the evaluation over the Italian test sites). However, this seems to be challenging in our experiments. Another important factor that influences regional DA diagnostics is the irrigation fraction information. This information was lacking in the GRIPC input for the pilot site in Germany, which forced us to simulate irrigation only over pixels where known irrigated fields were located, notwithstanding that also other cropland pixels could be irrigated, especially during the drier conditions that affected the northern countries during the 2018 summer months in northern European countries (i.e., the 2018 north-western Europe drought; Drouard et al., 2019). The standard deviation of normalized O-F higher than unity in the eastern area of the German pilot site could thus be related to the absence of irrigation simulations over areas which are actually irrigated. The lack of updated irrigation fraction input at global scale is still a strong limitation, although many studies have focused on monitoring irrigated lands worldwide in the last decade (Ambika et al., 2016; Bazzi et al., 2020; Dari et al., 2020; Gao et al., 2018). In the test site analysis, we focused on three different aspects: i) the added value of the DA experiments compared to the OL runs and the role of the Sentinel- $1 \gamma^{0}$ polarization; ii) the limitation of the Noah-MP parameterization and, more generally, of the DA system in improving irrigation simulations; and finally, iii) the spatial scale difference between the irrigation benchmark and irrigation simulations.

475 In Italy, we found an improvement due to DA in terms of SSM, LAI and ET, compared against RS retrievals (i.e., ASCAT SSM, PROBA-V LAI and MODIS ET). Sentinel-1 $\gamma^{0} \mathrm{VV}$ DA provided a larger contribution to SSM performances whereas Sentinel-1 $\gamma^{0}$ VH DA improved mostly the vegetation and vegetation-related states (LAI and ET). This could be expected based on previous literature (i.e., Bauer-Marschallinger et al., 2018; Vreugdenhil et al., 2020, 2018) and the previous study by 
Modanesi et al. (2021) over the Italian test sites. Our findings also showed how the Sentinel-1 $\gamma^{0}$ VV DA has a larger impact on the temporal dynamics of irrigation, whereas the VH polarization has a stronger influence in adjusting the bias and one potential reason could be the high sensitivity of the vegetation to root-zone soil moisture and vice versa (Modanesi et al., 2021).

Following the rationale that weather forecasts would be improved if land surface conditions are better constrained, the hope was to also improve irrigation forecasts with better constrained land surface conditions. However, the latter is only true if the assumption holds that the irrigation model produces the best irrigation estimates for the best estimates of land surface state variables. The latter assumption strongly depends on a good characterization of soil, vegetation and irrigation parameters which was found to be a limitation for the DA system. For instance, the OL run provided a large overestimation or underestimation of the irrigation quantities (depending on the study area) that can be attributed to limited parameterization of the irrigation scheme like for instance, detailed information on irrigation fraction input, dynamic crop rotation and rooting depths, as well as a poor description of the crop phenology in Noah-MP. The DA experiments helped in reducing the irrigation overestimation (or underestimation) at some, but not all, sites. This means that if the sprinkler irrigation scheme is not well parameterized the DA system is not able to strongly correct the OL runs. In case of biased state variables or flux simulations, it is generally more interesting to study the effect of DA on anomalies from (multi-year) climatological conditions, but such an analysis could not be performed with the limited amount of available benchmark data.

495 The limited spatial coverage and scale of the benchmark data is another reason of concern in the evaluation of the DA results. The Sentinel-1 DA appears to degrade the temporal dynamics (Pearson-R) of the bi-weekly irrigation estimates relative to the OL, when compared to small-scale (Budrio) benchmark. This can be explained by the spatial mismatch between the 1-km Sentinel-1 signal (which can include multiple fields irrigated at different times) and the irrigation information related to the small Budrio fields. However, this degradation is not significant or not found, when the simulations at multiple LIS pixels are aggregated (Faenza) or the statistics for multiple sites are lumped (Niedersachsen), respectively. In Germany, the median Pearson-R over the irrigated pixels increased especially for the Sentinel-1 $\gamma^{0}$ VV DA experiment, and a reduction of the median bias was found for the Sentinel-1 $\gamma^{0}$ VH DA experiment.

\subsection{Limitations and shortcomings}

The evaluation highlighted many aspects that can be improved for a more reliable irrigation estimation in a DA system which involves the Noah-MP LSM, with an irrigation scheme and innovative Sentinel-1 $\gamma^{0}$ observations. Although we obtained good results in terms of average DA diagnostics, it should be noted that the system is influenced by errors from the LSM, the irrigation scheme and the observation operator, which can interact and compensate each other providing suboptimal assimilation results. Based on Modanesi et al., (2021) the best unbiased WCM parameters were obtained, but a single parameters set was used for each model grid cell regardless of the crop type year variability. Especially, over the Po Valley, agricultural practices are characterized by crop rotation and the different structural effects of crop types on $\gamma^{0}$ observations can lead to an interannual variability that is only partly represented by soil moisture and LAI, and that could deteriorate model 
estimates (i.e., irrigation) in the DA runs. Additionally, the Sentinel-1 $\gamma^{0}$ data show slightly different statistics for different orbits and their combination results in a reduction of the signal-to-noise ratio, impacting time series analysis. We think that the inclusion of dynamic crop information and the assimilation of $\gamma^{0}$ data per orbit would improve the results and this is a future step of this work that we are currently investigating.

In terms of irrigation simulations, we found that absolute irrigation amounts and timing of irrigation estimated by the irrigation scheme strongly depend on soil (e.g., texture), vegetation (e.g., crop type) and irrigation (e.g., 'intensity' or area fraction) parameters. These parameters are now based on global datasets that might not be ideal for regional to local applications, being not dynamic and updated. Likewise, irrigation estimates depend on a correct representation of natural forcing input, here reanalysis data, which is unlikely to be accurate at the local scale (where the weather is itself influenced by irrigation). Furthermore, the irrigation estimates obtained with inclusion of DA are not always outperforming the model-only estimates. The main reason is that the irrigation model does not necessarily produce the best irrigation estimates for the best estimates of land surface state variables at the test sites. Thus, in line with the suggestions by Lawston et al. (2017), besides optimizing the DA itself, future research should also focus on improving the irrigation model to optimally use the observational information contained in the Sentinel-1 $\gamma^{0}$.

Another important aspect is related to the temporal and spatial variability of irrigation. We found that irrigation results become increasingly uncertain (and depend more on the irrigation parameterization) at shorter, e.g., daily, timescales. Soil moisture and vegetation increments can indeed affect the irrigation dynamics at short-term periods (i.e., daily time scale), and the benchmark data are also not representative of the effective irrigation needs at the short-term because of water management policies. It can be expected that the interannual variability in irrigation can be better estimated, as also suggested by Lawston et al. (2017). Furthermore, we found that the agreement between benchmark data and simulations of irrigation quantities increases in an analysis at pixel-level or at small-district spatial scale (Italy), showing the limitation of the system in providing information at plot scale, when simulations and RS observations are provided at coarser spatial resolution (i.e., $0.01^{\circ}$ ).

Three last aspects need to be highlighted: i) a robust evaluation analysis of land surface variables is not straightforward considering that RS observations at coarse spatial resolution (i.e., ASCAT) or constrained by reanalysis data (i.e., MODIS ET) do not necessarily provide accurate information on irrigation (Zaussinger et al., 2019); ii) additionally, evaluating irrigation estimates is also more challenging due to the scarce availability of information on the irrigation management (Massari et al., 2021); and iii) finally, the disagreement between in situ reference data and irrigation estimates obtained from the model-only can be partly explained by the actual in situ irrigation system management, which depends on water availability and policies unknown by the modelling system. In this context, although irrigation data are compared at bi-weekly time scale and DA is overall expected to improve the simulation of irrigation temporal dynamics, the temporal resolution of Sentinel-1 ( 3 days over the study areas) could imply missing some irrigation events and affect the DA results. 


\section{CONCLUSIONS}

Information on the actual irrigation quantities used for agricultural purposes is still missing and a correct quantification of irrigation is a challenging topic. The joint use of models and RS observations (which contain irrigation information) can help to fill this gap, while also providing irrigation estimates at high temporal scale and medium-high spatial resolution.

In this study we assimilated, in two different experiments, $1 \mathrm{~km}$ Sentinel-1 $\gamma^{0} \mathrm{VV}$ and VH polarization into the Noah-MP LSM, equipped with a sprinkler irrigation scheme, for the joint update of soil moisture and vegetation state variables. The objective was to test if irrigation water amounts, simulated by the irrigation scheme, can be optimally estimated when optimal soil moisture and vegetation estimates are available through DA. Additionally, we aimed at: i) testing the consistency of the DA system; ii) the effects of DA on irrigation and model state predictions with a specific focus on differences due to the ingestion of Sentinel-1 $\gamma^{0}$ in co- or cross-polarization; and finally, ii) unveiling the limitations of the system in terms of input parameters, DA shortcomings, spatial scale analysis and benchmark uncertainties.

The main conclusions drawn from our evaluation highlight shortcomings of the system and can be summarized as follows:

- The developed DA system is consistent and close to optimality, but it could benefit from enhanced model inputs, such as more reliable soil texture maps or the introduction of dynamic and high-resolution crop maps which could improve both soil moisture and vegetation simulations (input for the WCM calibration). Additional effort will also be needed in future research to account for different Sentinel-1 orbits, both in the WCM calibration and in the DA system, which will provide a gain of the signal-to-noise ratio with a general benefit in time series analysis.

- The Sentinel-1 $\gamma^{0}$ observations contain useful information about SSM and LAI over irrigated areas, confirming Modanesi et al. (2021), and the $\gamma^{0}$ polarization has a considerable influence on the DA results. For instance, the Sentinel-1 $\gamma^{0}$ VV DA mainly improves temporal dynamics of SSM and irrigation, whereas the Sentinel-1 $\gamma^{0}$ VH DA seem to have a stronger influence on vegetation and in adjusting temporary biases. We hypothesize that this could be due to the high sensitivity of the vegetation to root-zone soil moisture (and vice versa) but further investigation is needed to understand if the main impact comes from the stronger vegetation updating or the potential stronger updates in root-zone soil moisture.

- The Noah-MP LSM input and irrigation parameterization affect the OL and DA estimates, providing strong over- or underestimations of irrigation, depending on the study area. Those limitations are mainly related to soil texture uncertainties, lack of crop type inputs and outdated irrigated fractional area information, which affect the results of the reference OL run. In this context, the DA can only correct the estimates of irrigation amounts, if the irrigation simulation is not excessively biased, meaning that future research should focus on improving the irrigation model. Alternatively, even with biased irrigation simulations, the DA should be able to correct for the interannual variability in irrigation estimates, but the record of available benchmark data on irrigation is insufficient at this time to confirm this hypothesis. 
https://doi.org/10.5194/hess-2022-61

Preprint. Discussion started: 2 March 2022

(c) Author(s) 2022. CC BY 4.0 License.

- When comparing irrigation simulations and benchmark data, the spatial and temporal resolution play an important role. Irrigation estimates were here evaluated at a bi-weekly scale, to limit the influence of short-term analysis increments on the activation of the irrigation scheme, and to reduce mismatches with benchmark data due to human choices in the timing of irrigation application. In any case, results in terms of temporal dynamics and bias could also be affected by the temporal resolution of Sentinel-1 observations ( $\sim 3$ days) which could miss some daily irrigation events. Additional improvements could be obtained in DA analysis with higher-temporal resolution products as also demonstrated by Azimi et al. (2020). Furthermore, the evaluation in terms of irrigation quantities provides better results when irrigation benchmark data and the model have a similar spatial resolution. Evaluation is generally difficult due to the scant reporting of irrigation and extra uncertainty can derive from the reliability of in situ irrigation estimates.

585 This study points out that future efforts will be needed to improve irrigation estimates through the joint use of LSMs and Sentinel-1 observations, to allow a more realistic description of the hydrological cycle and more reliable irrigation simulations over irrigated areas. 


\section{ACKNOWLEDGEMENT}

The Authors would like to thank the European Space Agency (ESA) for the funding support as part of the IRRIGATION+ project (contract n. 4000129870/20/I-NB). For details, please visit https://esairrigationplus.org/. Additional acknowledgements go to the Canale Emiliano Romagnolo (CER; Emilia Romagna, Italy) for providing irrigation data over the irrigated test sites in Italy and to Claas Nendel from the Leibniz Centre for Agricultural Landscape Research (ZALF) for providing irrigation data over Germany. The Authors want to acknowledge the Vlaams Supercomputer Centrum (VSC) High Performance Computing (HPC) for providing the computational resources needed to realize this study (https://www.vscentrum.be/). Sara Modanesi would additionally acknowledge the Italian National Research Council (CNR) Short Term Mobility (STM) 2020 program which funded a month of permanence in Leuven to ultimate this research.

\section{References}

Albergel, C., Munier, S., Bocher, A., Bonan, B., Zheng, Y., Draper, C., Leroux, D.J., Calvet, J.-C., 2018. LDAS-Monde sequential assimilation of satellite derived observations applied to the contiguous US: An ERA-5 driven reanalysis of the land surface variables. Remote Sensing 10, 1627.

Alter, R.E., Im, E.-S., Eltahir, E.A., 2015. Rainfall consistently enhanced around the Gezira Scheme in East Africa due to irrigation. Nature Geoscience 8, 763-767.

Ambika, A.K., Wardlow, B., Mishra, V., 2016. Remotely sensed high resolution irrigated area mapping in India for 2000 to 2015. Scientific data 3, 1-14.

Attema, E.P.W., Ulaby, F.T., 1978. Vegetation modeled as a water cloud. Radio Sci. 13, 357-364. https://doi.org/10.1029/RS013i002p00357

Azimi, S., Dariane, A.B., Modanesi, S., Bauer-Marschallinger, B., Bindlish, R., Wagner, W., Massari, C., 2020. Assimilation of Sentinel 1 and SMAP-based satellite soil moisture retrievals into SWAT hydrological model: the impact of satellite revisit time and product spatial resolution on flood simulations in small basins. Journal of hydrology 581, 124367.

Bauer-Marschallinger, B., Freeman, V., Cao, S., Paulik, C., Schaufler, S., Stachl, T., Modanesi, S., Massari, C., Ciabatta, L., Brocca, L., 2018. Toward global soil moisture monitoring with Sentinel-1: Harnessing assets and overcoming obstacles. IEEE Transactions on Geoscience and Remote Sensing 57, 520-539.

Bazzi, H., Baghdadi, N., Fayad, I., Zribi, M., Belhouchette, H., Demarez, V., 2020. Near Real-Time Irrigation Detection at Plot Scale Using Sentinel-1 Data. Remote Sensing 12, 1456. https://doi.org/10.3390/rs12091456

Bechtold, M., De Lannoy, G.J.M., Reichle, R.H., Roose, D., Balliston, N., Burdun, I., Devito, K., Kurbatova, J., Strack, M., Zarov, E.A., 2020. Improved groundwater table and L-band brightness temperature estimates for Northern Hemisphere peatlands using new model physics and SMOS observations in a global data assimilation framework. Remote Sensing of Environment 246, 111805.

Brocca, L., Tarpanelli, A., Filippucci, P., Dorigo, W., Zaussinger, F., Gruber, A., Fernández-Prieto, D., 2018. How much water is used for irrigation? A new approach exploiting coarse resolution satellite soil moisture products. International journal of applied earth observation and geoinformation 73, 752-766.

Buchhorn, M., Lesiv, M., Tsendbazar, N.-E., Herold, M., Bertels, L., Smets, B., 2020. Copernicus global land cover layerscollection 2. Remote Sensing 12, 1044.

Busschaert, L., de Roos, S., Thiery, W., Raes, D., De Lannoy, G.J.M., 2022. Net irrigation requirement under different climate scenarios using AquaCrop over Europe. Hydrology and Earth System Sciences Discussions 1-30. https://doi.org/10.5194/hess-2021-631

Ceppi, A., Ravazzani, G., Corbari, C., Salerno, R., Meucci, S., Mancini, M., 2014. Real-time drought forecasting system for irrigation management. Hydrology and Earth System Sciences 18, 3353-3366. https://doi.org/10.5194/hess-18-33532014 
https://doi.org/10.5194/hess-2022-61

Preprint. Discussion started: 2 March 2022

(c) Author(s) 2022. CC BY 4.0 License.

Chen, F., Dudhia, J., 2001. Coupling an advanced land surface-hydrology model with the Penn State-NCAR MM5 modeling system. Part I: Model implementation and sensitivity. Monthly weather review 129, 569-585.

Chen, F., Mitchell, K., Schaake, J., Xue, Y., Pan, H.-L., Koren, V., Duan, Q.Y., Ek, M., Betts, A., 1996. Modeling of land surface evaporation by four schemes and comparison with FIFE observations. Journal of Geophysical Research: Atmospheres 101, 7251-7268.

Dari, J., Brocca, L., Quintana-Seguí, P., Escorihuela, M.J., Stefan, V., Morbidelli, R., 2020. Exploiting high-resolution remote sensing soil moisture to estimate irrigation water amounts over a Mediterranean region. Remote Sensing 12, 2593.

Dari, J., Quintana-Seguí, P., Escorihuela, M.J., Stefan, V., Brocca, L., Morbidelli, R., 2021. Detecting and mapping irrigated areas in a Mediterranean environment by using remote sensing soil moisture and a land surface model. Journal of Hydrology 596, 126129.

De Lannoy, G.J., Reichle, R.H., 2016. Global assimilation of multiangle and multipolarization SMOS brightness temperature observations into the GEOS-5 catchment land surface model for soil moisture estimation. Journal of Hydrometeorology 17, 669-691.

De Lannoy, G.J., Reichle, R.H., Vrugt, J.A., 2014. Uncertainty quantification of GEOS-5 L-band radiative transfer model parameters using Bayesian inference and SMOS observations. Remote Sensing of Environment 148, 146-157.

De Rosnay, P., Polcher, J., Laval, K., Sabre, M., 2003. Integrated parameterization of irrigation in the land surface model ORCHIDEE. Validation over Indian Peninsula. Geophysical Research Letters 30.

Drouard, M., Kornhuber, K., Woollings, T., 2019. Disentangling dynamic contributions to summer 2018 anomalous weather over Europe. Geophysical Research Letters 46, 12537-12546.

Druel, A., Munier, S., Mucia, A., Albergel, C., Calvet, J.-C., 2021. Implementation and validation of a new irrigation scheme in the ISBA land surface model. Geoscientific Model Development Discussions 1-47. https://doi.org/10.5194/gmd2021-332

Evans, J.P., Zaitchik, B.F., 2008. Modeling the large-scale water balance impact of different irrigation systems. Water Resources Research 44.

Evensen, G., 2003. The ensemble Kalman filter: Theoretical formulation and practical implementation. Ocean dynamics 53, 343-367.

Evensen, G., 1994. Sequential data assimilation with a nonlinear quasi-geostrophic model using Monte Carlo methods to forecast error statistics. Journal of Geophysical Research: Oceans 99, 10143-10162.

660 Fang, L., Zhan, X., Hain, C.R., Liu, J., 2018. Impact of using near real-time green vegetation fraction in Noah land surface model of NOAA NCEP on numerical weather predictions. Advances in Meteorology 2018.

Ferrant, S., Selles, A., Le Page, M., AlBitar, A., Mermoz, S., Gascoin, S., Bouvet, A., Ahmed, S., Kerr, Y., 2019. Sentinel$1 \& 2$ for near real time cropping pattern monitoring in drought prone areas. application to irrigation water needs in telangana, south-india. International Archives of the Photogrammetry, Remote Sensing and Spatial Information Sciences 42, 285-292.

Foley, J.A., Ramankutty, N., Brauman, K.A., Cassidy, E.S., Gerber, J.S., Johnston, M., Mueller, N.D., O’Connell, C., Ray, D.K., West, P.C., Balzer, C., Bennett, E.M., Carpenter, S.R., Hill, J., Monfreda, C., Polasky, S., Rockström, J., Sheehan, J., Siebert, S., Tilman, D., Zaks, D.P.M., 2011. Solutions for a cultivated planet. Nature 478, 337-342. https://doi.org/10.1038/nature10452

Gao, Q., Zribi, M., Escorihuela, M.J., Baghdadi, N., Segui, P.Q., 2018. Irrigation mapping using Sentinel-1 time series at field scale. Remote Sensing 10, 1495.

Gelaro, R., McCarty, W., Suárez, M.J., Todling, R., Molod, A., Takacs, L., Randles, C.A., Darmenov, A., Bosilovich, M.G., Reichle, R., 2017. The modern-era retrospective analysis for research and applications, version 2 (MERRA-2). Journal of climate 30, 5419-5454.

675 Girotto, M., De Lannoy, G.J., Reichle, R.H., Rodell, M., Draper, C., Bhanja, S.N., Mukherjee, A., 2017. Benefits and pitfalls of GRACE data assimilation: A case study of terrestrial water storage depletion in India. Geophysical research letters 44, 4107-4115.

Gleick, P.H., 2003. Water use. Annual review of environment and resources 28, 275-314.

Haddeland, I., Heinke, J., Biemans, H., Eisner, S., Flörke, M., Hanasaki, N., Konzmann, M., Ludwig, F., Masaki, Y., Schewe, J., 2014. Global water resources affected by human interventions and climate change. Proceedings of the National Academy of Sciences 111, 3251-3256. 
https://doi.org/10.5194/hess-2022-61

Preprint. Discussion started: 2 March 2022

(c) Author(s) 2022. CC BY 4.0 License.

Jalilvand, E., Tajrishy, M., Hashemi, S.A.G.Z., Brocca, L., 2019. Quantification of irrigation water using remote sensing of soil moisture in a semi-arid region. Remote Sensing of Environment 231, 111226.

Kumar, S.V., Holmes, T.R., Bindlish, R., Jeu, R. de, Peters-Lidard, C., 2020. Assimilation of vegetation optical depth retrievals from passive microwave radiometry. Hydrology and Earth System Sciences 24, 3431-3450.

Kumar, S.V., Peters-Lidard, C.D., Mocko, D., Reichle, R., Liu, Y., Arsenault, K.R., Xia, Y., Ek, M., Riggs, G., Livneh, B., 2014. Assimilation of remotely sensed soil moisture and snow depth retrievals for drought estimation. Journal of Hydrometeorology 15, 2446-2469.

Kumar, S.V., Peters-Lidard, C.D., Santanello, J.A., Reichle, R.H., Draper, C.S., Koster, R.D., Nearing, G., Jasinski, M.F., 2015. Evaluating the utility of satellite soil moisture retrievals over irrigated areas and the ability of land data assimilation methods to correct for unmodeled processes. Hydrology and Earth System Sciences 19, 4463-4478.

Kumar, S.V., Reichle, R.H., Peters-Lidard, C.D., Koster, R.D., Zhan, X., Crow, W.T., Eylander, J.B., Houser, P.R., 2008. A land surface data assimilation framework using the land information system: Description and applications. Advances in Water Resources 31, 1419-1432.

Kustu, M.D., Fan, Y., Robock, A., 2010. Large-scale water cycle perturbation due to irrigation pumping in the US High Plains: A synthesis of observed streamflow changes. Journal of Hydrology 390, 222-244.

Lawston, P.M., Santanello Jr, J.A., Kumar, S.V., 2017. Irrigation signals detected from SMAP soil moisture retrievals. Geophysical Research Letters 44, 11-860.

Lawston, P.M., Santanello Jr, J.A., Zaitchik, B.F., Rodell, M., 2015. Impact of irrigation methods on land surface model spinup and initialization of WRF forecasts. Journal of Hydrometeorology 16, 1135-1154.

Lievens, H., Demuzere, M., Marshall, H.-P., Reichle, R.H., Brucker, L., Brangers, I., de Rosnay, P., Dumont, M., Girotto, M., Immerzeel, W.W., Jonas, T., Kim, E.J., Koch, I., Marty, C., Saloranta, T., Schöber, J., De Lannoy, G.J.M., 2019. Snow depth variability in the Northern Hemisphere mountains observed from space. Nature Communications 10 , 4629. https://doi.org/10.1038/s41467-019-12566-y

Lievens, H., Martens, B., Verhoest, N.E.C., Hahn, S., Reichle, R.H., Miralles, D.G., 2017a. Assimilation of global radar backscatter and radiometer brightness temperature observations to improve soil moisture and land evaporation estimates. Remote Sensing of Environment 189, 194-210.

Lievens, H., Reichle, R.H., Liu, Q., De Lannoy, G.J., Dunbar, R.S., Kim, S.B., Das, N.N., Cosh, M., Walker, J.P., Wagner, W., 2017b. Joint Sentinel-1 and SMAP data assimilation to improve soil moisture estimates. Geophysical research letters 44, 6145-6153.

Liu, C., Shi, J., 2016. Estimation of vegetation parameters of water cloud model for global soil moisture retrieval using timeseries L-band Aquarius observations. IEEE Journal of Selected Topics in Applied Earth Observations and Remote Sensing 9, 5621-5633.

Macelloni, G., Paloscia, S., Pampaloni, P., Marliani, F., Gai, M., 2001. The relationship between the backscattering coefficient and the biomass of narrow and broad leaf crops. IEEE Transactions on Geoscience and Remote Sensing 39, 873-884.

Mahrt, L., Pan, H., 1984. A two-layer model of soil hydrology. Boundary-Layer Meteorology 29, 1-20.

Massari, C., Modanesi, S., Dari, J., Gruber, A., De Lannoy, G.J., Girotto, M., Quintana-Seguí, P., Le Page, M., Jarlan, L., Zribi, M., 2021. A review of irrigation information retrievals from space and their utility for users. Remote Sensing $13,4112$.

720 Matthews, O.P., Germain, D.S., 2007. Boundaries and transboundary water conflicts. Journal of Water Resources Planning and Management 133, 386-396.

Modanesi, S., Massari, C., Gruber, A., Lievens, H., Tarpanelli, A., Morbidelli, R., De Lannoy, G.J.M., 2021. Optimizing a backscatter forward operator using Sentinel-1 data over irrigated land. Hydrology and Earth System Sciences 25, 6283-6307. https://doi.org/10.5194/hess-25-6283-2021

Monfreda, C., Ramankutty, N., Foley, J.A., 2008. Farming the planet: 2. Geographic distribution of crop areas, yields, physiological types, and net primary production in the year 2000. Global biogeochemical cycles 22.

Nie, W., Zaitchik, B.F., Rodell, M., Kumar, S.V., Arsenault, K.R., Li, B., Getirana, A., 2019. Assimilating GRACE into a land surface model in the presence of an irrigation-induced groundwater trend. Water Resources Research 55, 1127411294. 
Niu, G.-Y., Yang, Z.-L., Mitchell, K.E., Chen, F., Ek, M.B., Barlage, M., Kumar, A., Manning, K., Niyogi, D., Rosero, E., 2011. The community Noah land surface model with multiparameterization options (Noah-MP): 1. Model description and evaluation with local-scale measurements. Journal of Geophysical Research: Atmospheres 116.

Norman, J.M., Kustas, W.P., Humes, K.S., 1995. Source approach for estimating soil and vegetation energy fluxes in observations of directional radiometric surface temperature. Agricultural and Forest Meteorology 77, 263-293.

Ozdogan, M., Gutman, G., 2008. A new methodology to map irrigated areas using multi-temporal MODIS and ancillary data: An application example in the continental US. Remote Sensing of Environment 112, 3520-3537.

Ozdogan, M., Rodell, M., Beaudoing, H.K., Toll, D.L., 2010a. Simulating the effects of irrigation over the United States in a land surface model based on satellite-derived agricultural data. Journal of Hydrometeorology 11, 171-184.

Ozdogan, M., Yang, Y., Allez, G., Cervantes, C., 2010b. Remote sensing of irrigated agriculture: Opportunities and challenges. Remote sensing 2, 2274-2304.

Peel, M.C., Finlayson, B.L., McMahon, T.A., 2007. Updated world map of the Köppen-Geiger climate classification. Hydrology and earth system sciences 11, 1633-1644.

Peña-Arancibia, J.L., McVicar, T.R., Paydar, Z., Li, L., Guerschman, J.P., Donohue, R.J., Dutta, D., Podger, G.M., van Dijk, A.I., Chiew, F.H., 2014. Dynamic identification of summer cropping irrigated areas in a large basin experiencing extreme climatic variability. Remote sensing of environment 154, 139-152.

Pokhrel, Y., Hanasaki, N., Koirala, S., Cho, J., Yeh, P.J.-F., Kim, H., Kanae, S., Oki, T., 2012. Incorporating anthropogenic water regulation modules into a land surface model. Journal of Hydrometeorology 13, 255-269.

Reichle, R.H., De Lannoy, G.J., Liu, Q., Ardizzone, J.V., Colliander, A., Conaty, A., Crow, W., Jackson, T.J., Jones, L.A., Kimball, J.S., 2017. Assessment of the SMAP level-4 surface and root-zone soil moisture product using in situ measurements. Journal of Hydrometeorology 18, 2621-2645.

Reichle, R.H., Liu, Q., Koster, R.D., Crow, W.T., De Lannoy, G.J., Kimball, J.S., Ardizzone, J.V., Bosch, D., Colliander, A., Cosh, M., 2019. Version 4 of the SMAP Level-4 Soil Moisture algorithm and data product. Journal of Advances in Modeling Earth Systems 11, 3106-3130.

Reichle, R.H., McLaughlin, D.B., Entekhabi, D., 2002. Hydrologic data assimilation with the ensemble Kalman filter. Monthly Weather Review 130, 103-114.

Salmon, J.M., Friedl, M.A., Frolking, S., Wisser, D., Douglas, E.M., 2015. Global rain-fed, irrigated, and paddy croplands: A new high resolution map derived from remote sensing, crop inventories and climate data. International Journal of Applied Earth Observation and Geoinformation 38, 321-334.

Siebert, S., Döll, P., 2010. Quantifying blue and green virtual water contents in global crop production as well as potential production losses without irrigation. Journal of Hydrology 384, 198-217.

Strosser, P., Dworak, T., Garzon Delvaux, P.A., Berglund, M., Schmidt, G., Mysiak, J., Kossida, M., Iacovides, I., Ashton, V., 2012. Final Report Gap Analysis of the Water Scarcity and Droughts Policy in the EU European Commission. European Commission.

765 in Applied Earth Observations and Remote Sensing 7, 3473-3481.

Vreugdenhil, M., Navacchi, C., Bauer-Marschallinger, B., Hahn, S., Steele-Dunne, S., Pfeil, I., Dorigo, W., Wagner, W., 2020. Sentinel-1 cross ratio and vegetation optical depth: A comparison over Europe. Remote Sensing 12, 3404.

Vreugdenhil, M., Wagner, W., Bauer-Marschallinger, B., Pfeil, I., Teubner, I., Rüdiger, C., Strauss, P., 2018. Sensitivity of Sentinel-1 backscatter to vegetation dynamics: An Austrian case study. Remote Sensing 10, 1396.

Vrugt, J.A., Ter Braak, C.J., Clark, M.P., Hyman, J.M., Robinson, B.A., 2008. Treatment of input uncertainty in hydrologic modeling: Doing hydrology backward with Markov chain Monte Carlo simulation. Water Resources Research 44.

Wagner, W., Hahn, S., Kidd, R., Melzer, T., Bartalis, Z., Hasenauer, S., Figa-Saldaña, J., De Rosnay, P., Jann, A., Schneider, S., 2013. The ASCAT soil moisture product: A review of its specifications, validation results, and emerging applications, Meteorol. Z., 22, 5-33.

775 Zappa, L., Schlaffer, S., Bauer-Marschallinger, B., Nendel, C., Zimmerman, B., Dorigo, W., 2021. Detection and Quantification of Irrigation Water Amounts at 500 m Using Sentinel-1 Surface Soil Moisture. Remote Sensing 13, 1727. 
https://doi.org/10.5194/hess-2022-61

Hydrology and

Preprint. Discussion started: 2 March 2022

(c) Author(s) 2022. CC BY 4.0 License.

Zaussinger, F., Dorigo, W., Gruber, A., Tarpanelli, A., Filippucci, P., Brocca, L., 2019. Estimating irrigation water use over the contiguous United States by combining satellite and reanalysis soil moisture data. Hydrology and earth system sciences 23, 897-923.

Zribi, M., Chahbi, A., Shabou, M., Lili-Chabaane, Z., Duchemin, B., Baghdadi, N., Amri, R., Chehbouni, A., 2011. Soil surface moisture estimation over a semi-arid region using ENVISAT ASAR radar data for soil evaporation evaluation. Hydrology and Earth System Sciences 15, 345-358.

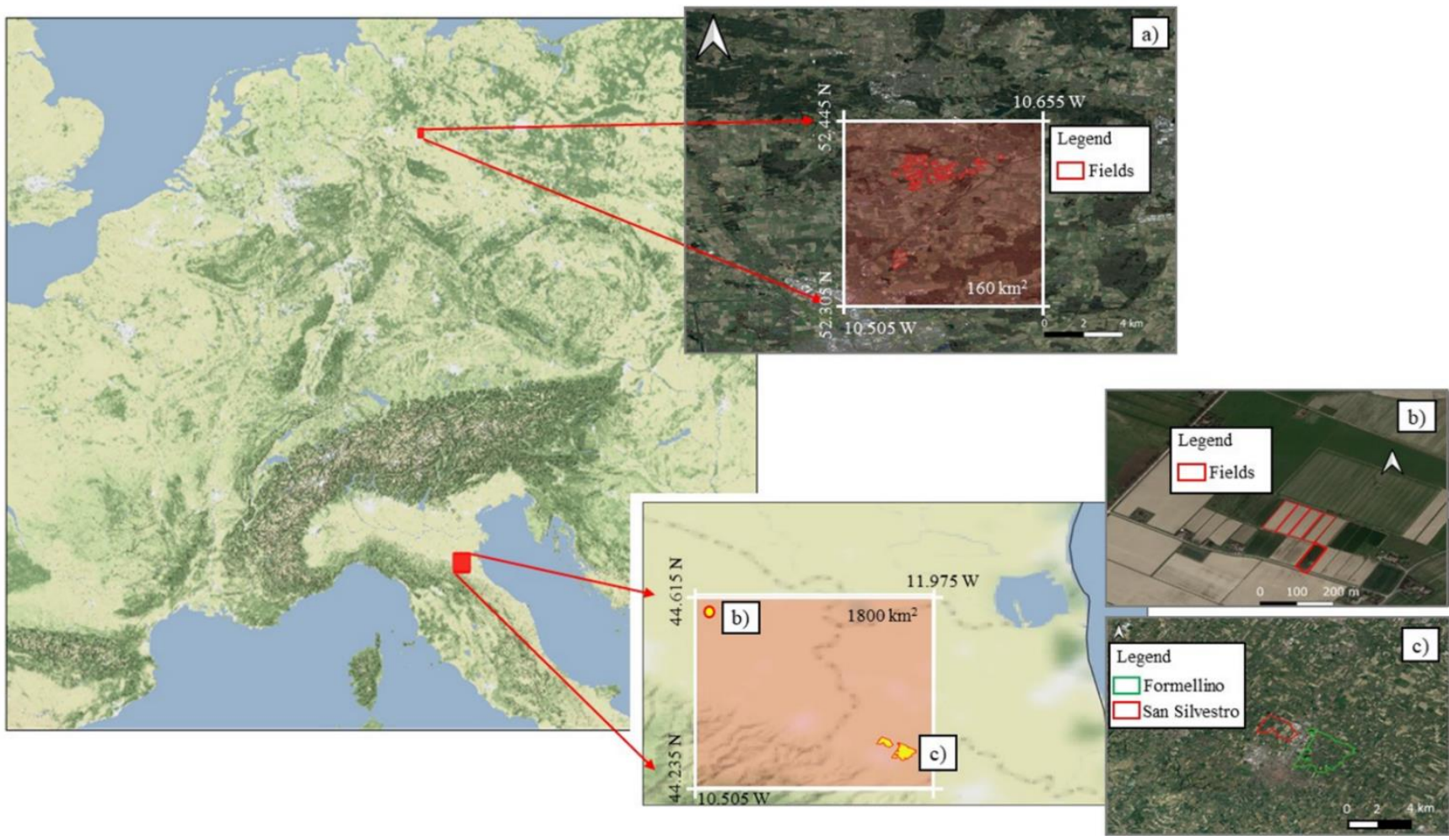

Figure 1: Study area composed by the German and Italian pilot sites (represented by the red boxes). The pilot sites include three test sites: a) Niedersachsen with 49 fields; b) five fields in Budrio; and c) two small districts close to the city of Faenza, called San Silvestro and Formellino. Map data (C) Google Maps 2019. 
https://doi.org/10.5194/hess-2022-61

Preprint. Discussion started: 2 March 2022

(c) Author(s) 2022. CC BY 4.0 License.
Hydrology and

Earth System

Sciences

Discussions

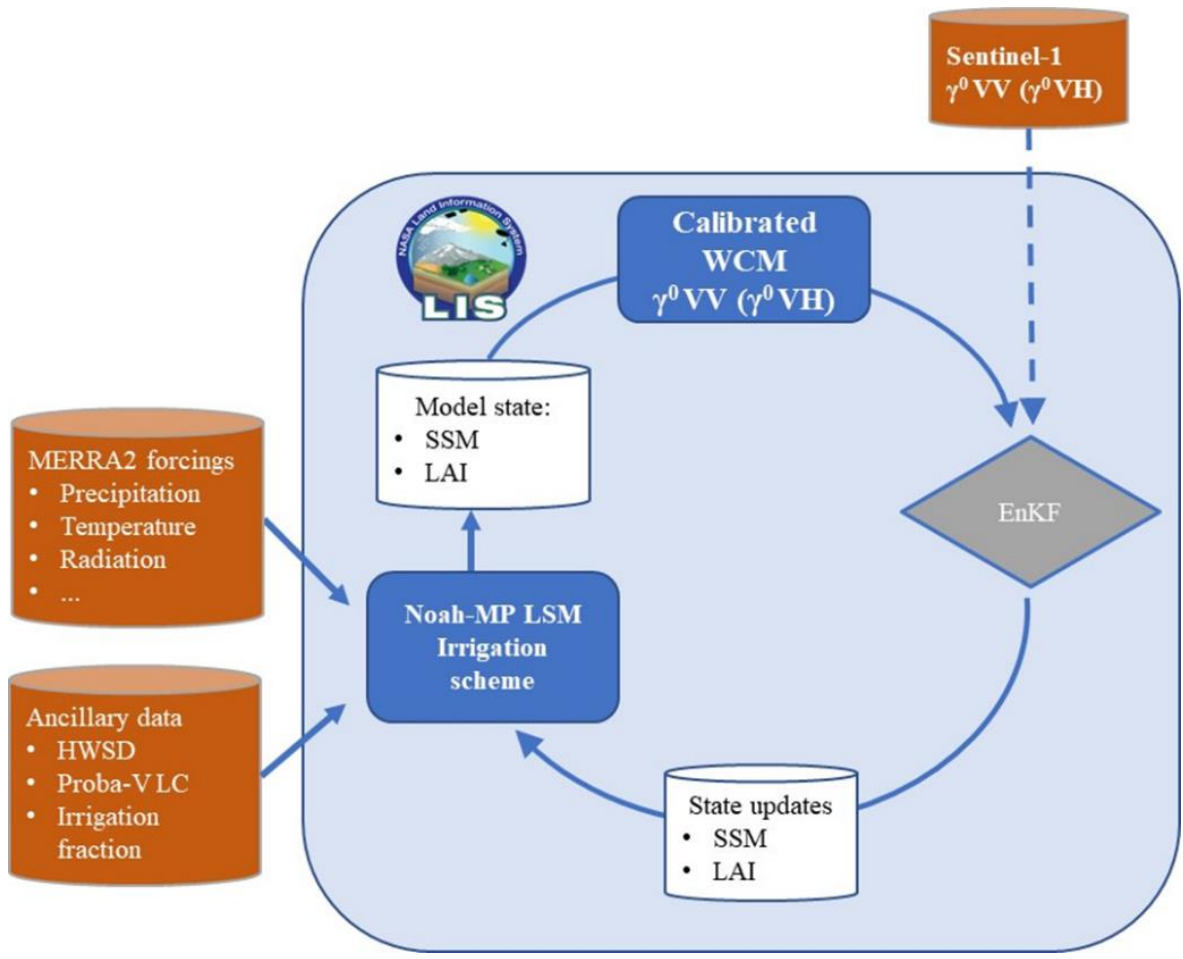

Figure 2: Workflow of the DA experiments realized within the LIS framework. The scheme describes how the Sentinel-1 $\gamma^{0}$ (VV or VH) is assimilated into the Noah-MP LSM to sequentially update SSM and LAI using an EnKF.
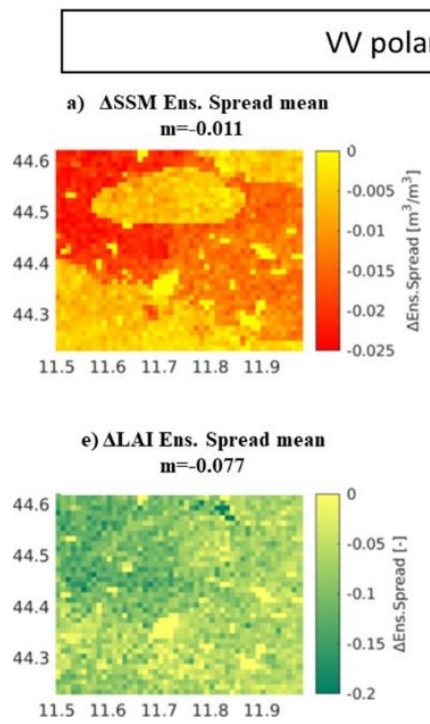

b) $\triangle$ SSM Ens, Spread mea
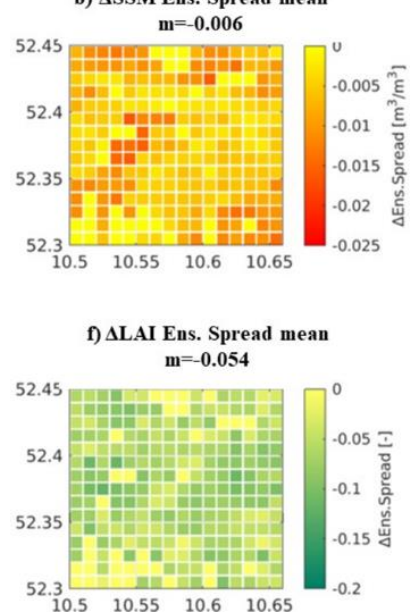
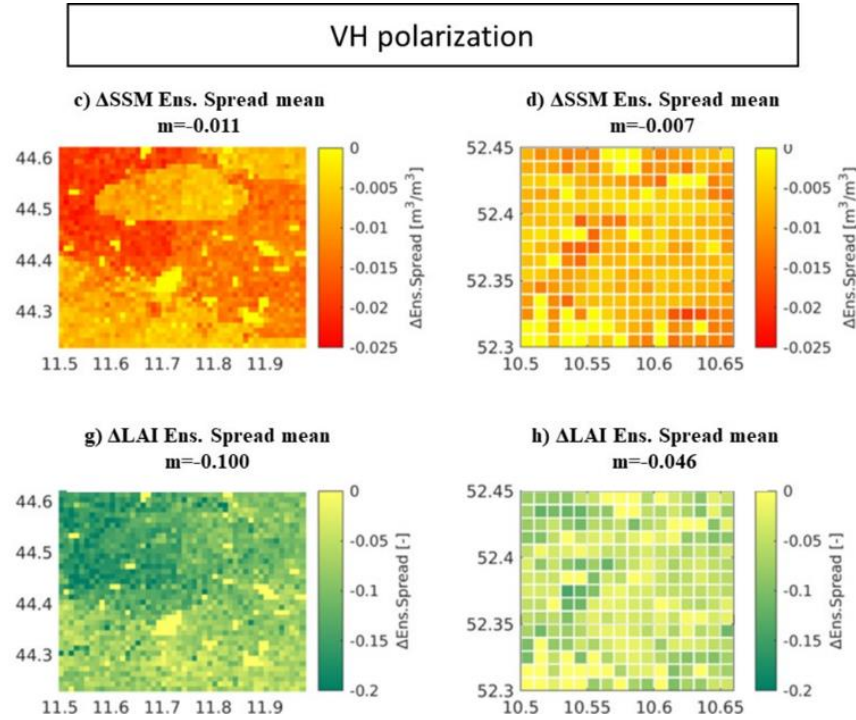

795 Figure 3: Maps of the difference in time-mean ensemble spread between the DA and OL runs for (top) SSM ( $\Delta$ SSM Ens. Spread) and (bottom) LAI ( $\triangle$ LAI Ens. Spread). $\triangle$ SSM Ens. Spread after Sentinel-1 $\gamma^{0}$ VV DA a) in Italy, b) in Germany; Sentinel-1 $\gamma^{0}$ VH DA c) in Italy, d) in Germany. (e, f, g, h) Similar to (a, b, c, d) but for $\Delta$ LAI Ens. Spread. $m$ is the mean over the entire study area. The reference period is January 2015-December 2020. 
https://doi.org/10.5194/hess-2022-61

Preprint. Discussion started: 2 March 2022

(c) Author(s) 2022. CC BY 4.0 License.
Hydrology and

Earth System

Sciences

Discussions
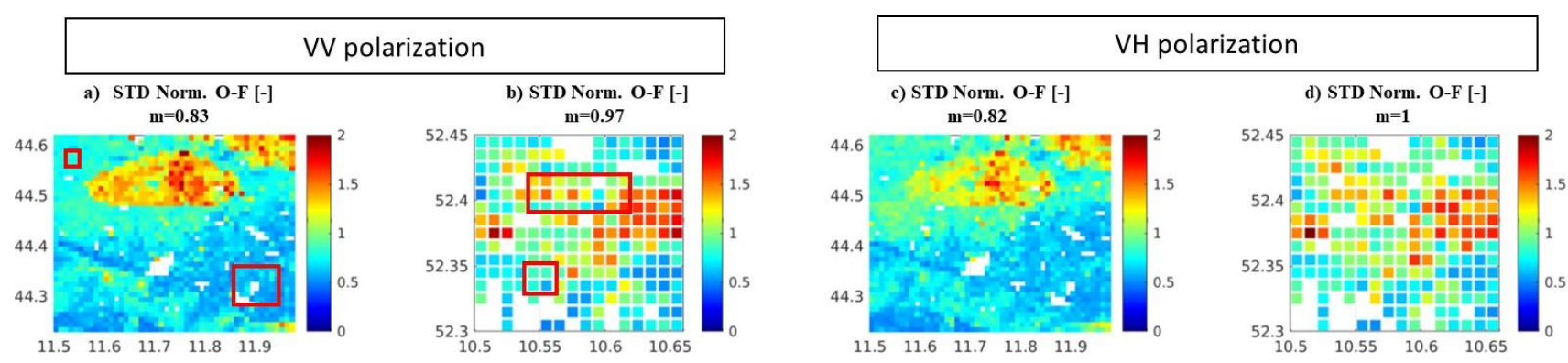

800 Figure 4: Maps of the standard deviation (STD) of the normalized O-F residuals for: Sentinel-1 $\gamma^{0}$ VV DA a) in Italy and b) in Germany; Sentinel-1 $\gamma^{0}$ VH DA c) in Italy and d) in Germany. $m$ is the mean over the entire study area. Red boxes in a) and b) indicate areas where the test sites are located. The reference period is January 2015-December 2020. No Sentinel-1 data were assimilated in the white areas (Figure S3).
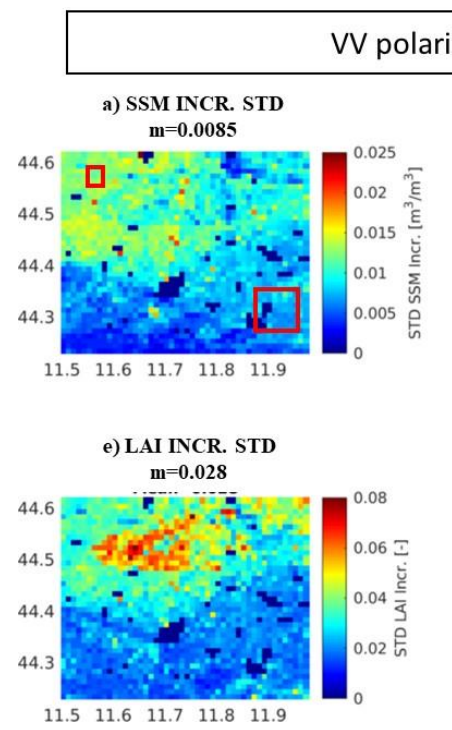
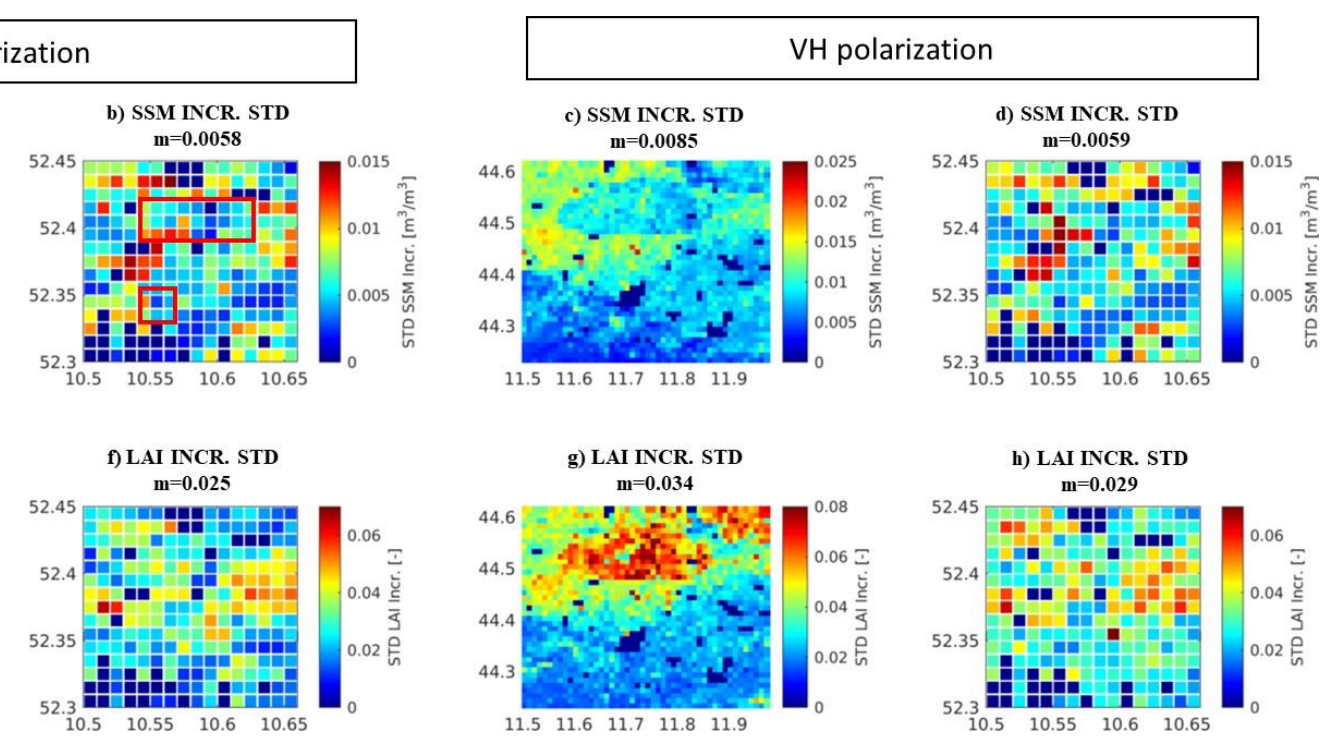

Figure 5: Same as Figure 3, but for the standard deviation (STD) of the increments in (top) SSM and (bottom) LAI. Red boxes in a) and b) indicate areas where the test sites are located. 
https://doi.org/10.5194/hess-2022-61
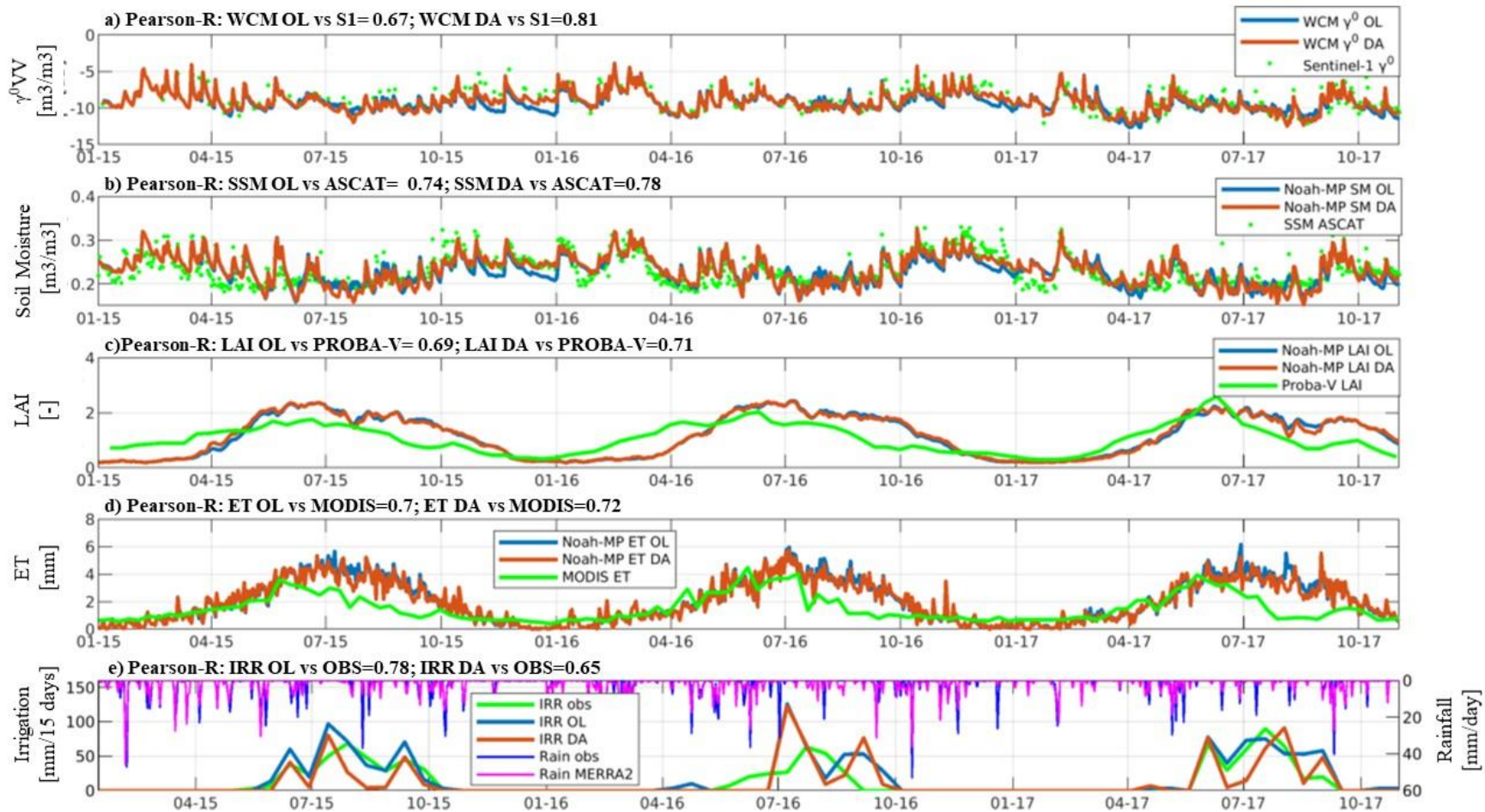

Figure 6: Evaluation of the OL (blue lines) and DA (orange lines) results at the Budrio test site for the Sentinel-1 $\gamma^{0}$ VV DA experiment: a) Sentinel-1 $\gamma^{0}$ VV against WCM $\gamma^{0}$ VV; b) ASCAT SSM against simulated SSM; c) Proba-V LAI against simulated LAI; d) MODIS ET against simulated ET; e) Irrigation benchmark against simulated irrigation, with an indication of MERRA2 and in situ rainfall estimates. 
https://doi.org/10.5194/hess-2022-61

Preprint. Discussion started: 2 March 2022

(c) Author(s) 2022. CC BY 4.0 License.
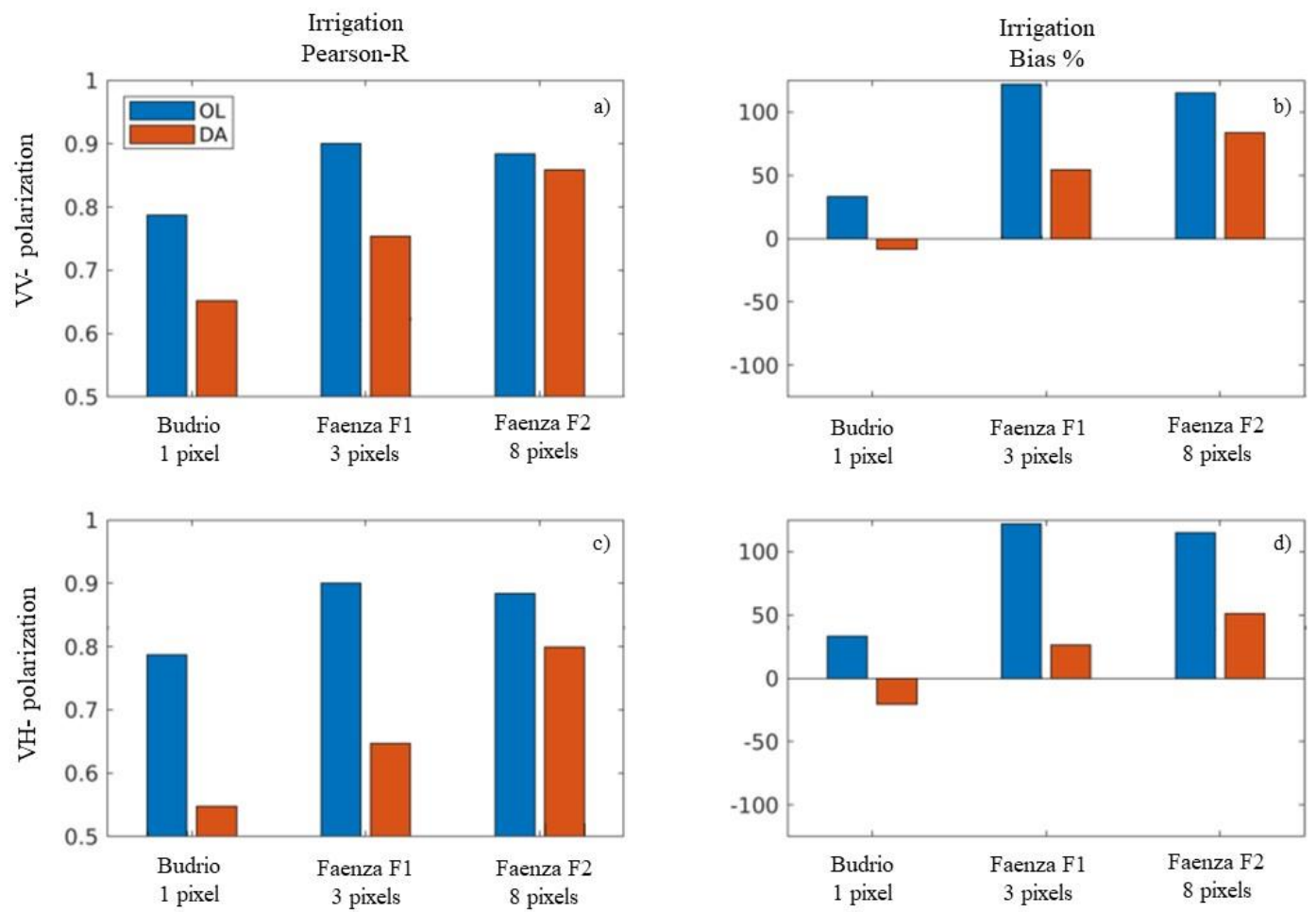

Figure 7: Evaluation results in terms of irrigation simulations for the three Italian test sites based on the extent of the fields in terms of LIS pixels. Blue bars refer to the OL run while orange bars refer to the DA run. The Pearson-R values are reported for: a) the Sentinel-1 $\gamma^{0}$ VV DA; and c) for the Sentinel-1 $\gamma^{0}$ VH DA experiments. (b, d) Same as (a, c), but for percentage bias. 
https://doi.org/10.5194/hess-2022-61

Preprint. Discussion started: 2 March 2022

(c) Author(s) 2022. CC BY 4.0 License.
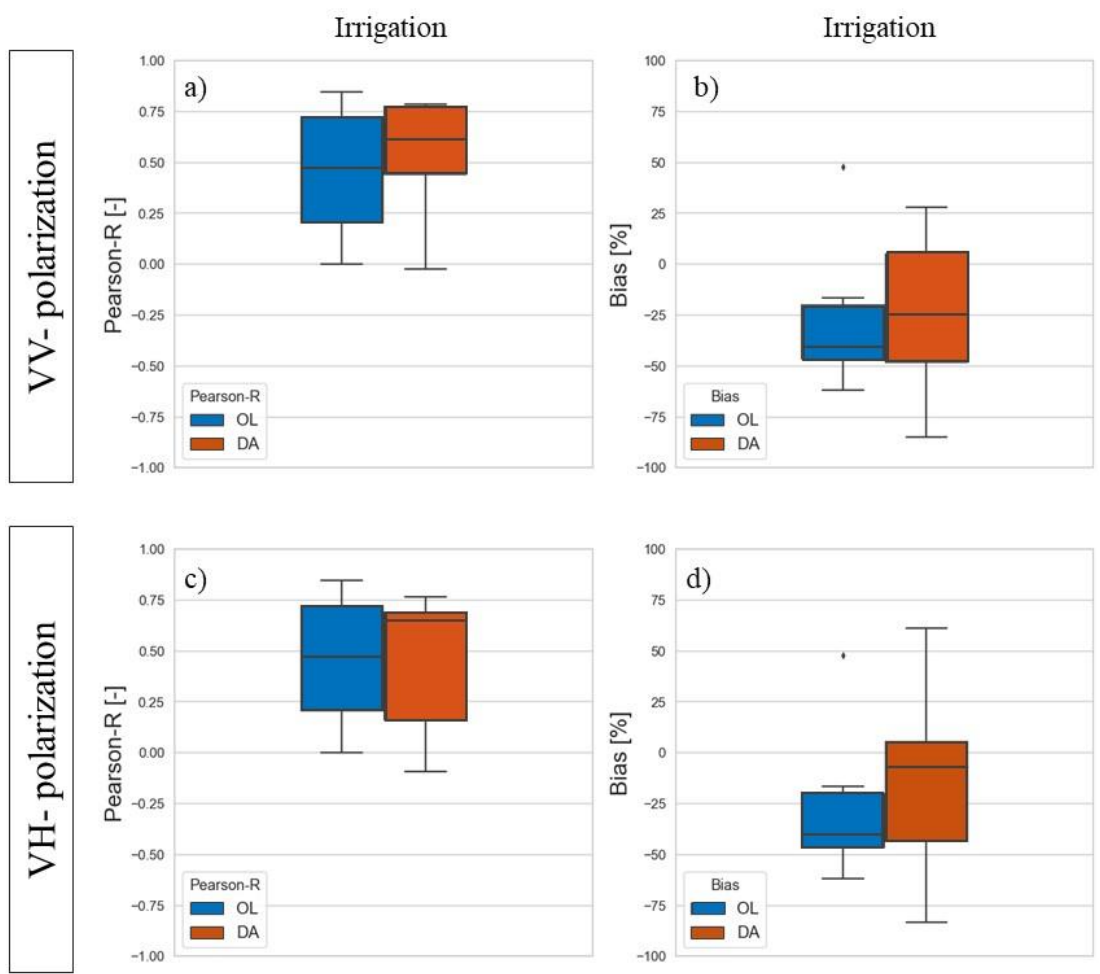

Figure 8: Evaluation in terms of (left) Pearson-R and (right) percentage bias of irrigation simulations for the German test sites, containing the 8 irrigated LIS pixels with percentage irrigated area larger than $25 \%$. Blue boxplots refer to the OL run while orange boxplots refer to the DA run, with (a-b) the Sentinel-1 $\gamma^{0}$ VV DA and (c-d) for the Sentinel-1 $\gamma^{0}$ VH DA. 
https://doi.org/10.5194/hess-2022-61

Preprint. Discussion started: 2 March 2022

(C) Author(s) 2022. CC BY 4.0 License.

\section{Code and Data availability.}

Data from ASCAT are available at the website http://hsaf.meteoam.it/

The Sentinel-1 backscatter data processing was done using the ESA Sentinel Application Platform (SNAP) and including standard processing techniques.

Data from PROBA-V are available at https://land.copernicus.eu/global/

MERRA-2 data are available at MDISC, managed by the NASA Goddard Earth Sciences (GES) Data and Information Services

Center (DISC, https://disc.gsfc.nasa.gov/datasets?project=MERRA-2)

MODIS ET from the MOD16A2 version is available from the freely accessible Google Earth Engine (GEE) platform.

830 LIS input and general parameters tables are provided at https://portal.nccs.nasa.gov/lisdata_pub/data/

In situ data are available under request to the original providers.

Author contributions: Sara Modanesi designed, coordinated the study and made the analyses. Christian Massari, Gabrielle

De Lannoy and Michel Bechtold designed, coordinated and helped in the data analysis and interpretation. Hans Lievens,

835 Angelica Tarpanelli, Luca Brocca and Luca Zappa helped in the results interpretation and data processing and collection. All authors contributed to the editing of the manuscript.

Competing interests. The authors declare no competing interest 